\title{
CONSUMPTION AND CREDIT: A MODEL OF TIME-VARYING LIQUIDITY CONSTRAINTS
}

\author{
Sydney Ludvigson \\ Federal Reserve Bank of New York \\ Research Paper No. 9624
}

August 1996

This paper is being circulated for purposes of discussion and comment only.

The contents should be regarded as preliminary and not for citation or quotation without permission of the author. The views expressed are those of the author and do not necessarily reflect those of the Federal Reserve Bank of New York or the Federal Reserve System.

Single copies are available on request to:

Public Information Department Federal Reserve Bank of New York New York, NY 10045 


\title{
Consumption and Credit: A Model of Time-Varying Liquidity Constraints
}

\author{
Sydney Ludvigson ${ }^{\dagger}$ \\ Federal Reserve Bank of New York
}

May 22, 1996

\begin{abstract}
I investigate the role of consumer credit in determining real consumption growth in aggregate, post-war, U.S. data. This paper presents evidence that predictable growth in consumer credit is significantly related to consumption growth. The finding is inconsistent with the predictions of, (i) the permanent income/life cycle hypothesis, (ii) "rule of thumb"models where some agents simply consume their current income, and (iii) models of liquidity constraints where individuals face a fixed borrowing limit. I argue that this finding calls for a reinterpretation of the excess sensitivity of consumption to current resources, and suggests a model of liquidity constraints in which the borrowing limitation is time-varying and dependent on current income. The theoretical framework rationalizes the importance of predictable credit growth in determining consumption growth. The model can also be employed to simulate the real effects of a one-time deregulation, or "evolution" in household credit markets. This exercise indicates that the (constraint induced) dependence of consumption on current resources may not be permanently eliminated when moderate amounts of additional credit are made available. Furthermore, the expansion generates a short term boom in consumption.
\end{abstract}

† Domestic Research 3rd floor, 33 Liberty Street, New York, NY 10045, 212-720-6810, sydney.ludvigson@frbny.sprint.com. This paper appears as part of my Princeton University doctoral dissertation. I am grateful to Ben Bernanke, John Y. Campbell, and Angus Deaton for their advice and many valuable discussions, to Christopher Carroll, Karen Dynan, Jeffrey Furher, and Scott Shue for constructive suggestions, to seminar participants at many universities and conferences for helpful comments, and to the Alfred P. Sloan Foundation for financial support. The views expressed in the paper are those of the author and are not necessarily reflective of views at the Federal Reserve Bank of New York or the Federal Reserve System. Any errors or omissions are the responsibility of the Author. 


\section{Introduction}

Consumer credit as a ratio to personal income has more than doubled over the past forty years, with particularly sharp and sustained increases occurring in the 1980's (Figure 1). This intensive use of consumer credit has recently lead to considerable speculation over a variety of ways in which consumer indebtedness may have independent influence on real consumption expenditure. While the nature of consumer credit use has undoubtedly changed in recent years, any supposition that consumer indebtedness is behaving as a causal factor in determining real activity raises both empirical and theoretical questions. On the empirical side, what, if any, are the qualitative dynamic effects of consumer credit on consumption, how should they be characterized, and how recent are they? From a theoretical point of view, such effects, if they existed, would seem to be at odds with standard consumer theory, which assumes rational, forward-looking individuals whose demand for credit passively responds to their demand for consumption. What kind of theoretical framework can be employed to think about how variation in consumer credit might instead influence consumption?

The purpose of this paper is twofold. First, it documents empirical results about the relationship between consumer installment credit and consumption that are difficult to reconcile with much existing consumer theory. One principal finding is that consumption growth is significantly correlated with predictable consumer credit growth. These empirical results motivate the second goal of the paper, which is to provide a theoretical framework for thinking about how changes in consumer credit might influence the time series properties of consumption at both the individual and aggregate levels. I propose a model of time-varying liquidity constraints and solve the consumer's problem when the borrowing limit is tied to current income, rather than making a more standard presumption that indebtedness cannot exceed some fixed amount. In order to both place the empirical results in context, and motivate the theoretical analysis, it may be useful to begin by briefly and incompletely reviewing some relevant contributions made to the macroeconomic literature on consumption. 


\section{$1.1 \quad$ Literature Review}

The earliest and best-known study of the stochastic properties of the life cycle-permanent income hypothesis is that of Robert Hall (1978). He demonstrated an important implication of rational, forward-looking, decision making: when the real interest rate is constant, the conditional expectation of future marginal utility is determined solely by today's level of consumption. Hall concluded that a close approximation to the stochastic behavior of consumption under the permanent income hypothesis (PIH) was that, conditional on lagged consumption, no other variable observed in earlier periods should have predictive power for consumption. The major methodological insight was that these implications could be tested directly, without the need to specify a particular functional form for consumption, or the relation of current and past income to expected future income. Hall found no association between consumption and most lagged variables (including income) conditional on lagged consumption, a result consistent with the permanent income hypothesis.

Since that study, others have tested the PIH using alternative approaches, and have consistently found evidence against such a representative agent framework. Flavin (1981) formulates a structural model of consumption which has the advantage of making explicit the role of current income in signaling changes in permanent income. She rejects the permanent income hypothesis by finding that changes in consumption are positively linked to lagged changes in income, a result often referred to as the "excess sensitivity" of consumption to lagged, or predictable income. At the micro level, Hall and Mishkin (1982) use data from the Panel Study of Income Dynamics to study the behavior food consumption; they interpret their results as implying that approximately 80 percent of consumption follows the PIH theory, and the remaining 20 percent simply tracks current total income passively. Finally, using a framework that I employ below, Campbell and Mankiw (1989, $1991)$ find that changes in aggregate consumption are related to predictable changes in income. Both Hall and Mishkin and Campbell and Mankiw suggest that the presence of so-called "rule of thumb" consumers may be an explanation for their findings. They conclude the data are generated by two types of consumers: those who are forward-looking and consume their permanent income, 
and "rule of thumb consumers" who simply consume their current income in every period.

The so-called excess sensitivity findings have been widely interpreted as representing a violation of optimal intertemporal allocation in the absence of borrowing constraints. ${ }^{1}$ Hence one explanation for rule of thumb behavior, and for failures of the PIH in general, is the presence of liquidity constraints. The usual assumption in these models is that borrowing cannot exceed some fixed amount. Such restrictions do not necessarily lead to rule of thumb behavior, except under special assumptions about the stochastic properties of income.(Deaton 1992). However, Zeldes (1989) finds more obvious violations of the consumer's first order conditions for individuals who are more likely to be constrained, lending support to the idea that borrowing limitations are a likely explanation for failures of the PIH.

This brief review suggests that issues of credit availability have long been an important part of explaining previously documented correlations between consumption growth and predictable components of income. In the next section of the paper, however, I. argue that the findings documented here on consumption and household credit are not likely to be consistent with the models discussed above, and suggest instead an alternative model of liquidity constraints which can at least qualitatively account for both the new and preexisting evidence.

\section{$1.2 \quad$ Findings}

Using U.S. aggregate data this paper presents evidence that consumer credit has important effects on consumption; in particular, the growth in predictable consumer credit is a significant determinant of consumption growth.

This finding is inconsistent with popular formulations of the permanent income hypothesis dis-

\footnotetext{
${ }^{1}$ For a dissenting opinion, see Carroll (1991). He argues that a forward-looking model with precautionary saving motives, where consumers are impatient and face a great deal of uncertainty, can in principle explain the findings of excess sensitivity without liquidity constraints or sub-optimal behavior. With precautionary motives, the growth in consumption should be related to the variance of consumption which he shows is endogenous. However, much of the previous and existing literature has assumed this variance to be approximately constant, and has sought other explanations for the findings of excess sensitivity.
} 
cussed above, according to which the change in consumption is, at least to an approximation, unforecastable. ${ }^{2}$ In these models, no variable known in earlier periods other than the expected real interest rate should be related to the change in consumption. Variables in today's information set should already be expressed in current period consumption, so that the growth in consumption ' should be unrelated to predictable credit growth just as it should be to predictable income growth.

The finding is also trivially inconsistent with "rule of thumb" consumption where some fraction of the population simply consumes their current income every period, a framework that rationalizes the relation between consumption growth and predictable income growth; predictable credit growth should have no explanatory power once predictable income growth is controlled for. ${ }^{3}$

Finally, though models of liquidity constraints where consumers face a fixed borrowing limit have been shown to explain the correlation between consumption growth and predictable income growth (Deaton, 1991), they will not likely produce a correlation between consumption growth and predictable credit growth. To see why, consider an extreme example of optimal consumption behavior subject to a fixed borrowing limit, where individuals are so impatient that they are constrained, borrowing up to their credit limit, in every period. In this case, consumption growth will be very highly correlated with predictable income growth, but not with predictable credit growth because actual borrowing (equal to the upper limit) is fixed.

It should be emphasized that this evidence does not represent a simple ex post correlation

\footnotetext{
${ }^{2}$ One such approximation is that marginal utility is linear and the real interest rate constant and equal to the rate of time preference. Others assume that the log, rather than the level, of consumption follows a martingale, (see Mankiw, 1981 and Hansen and Singleton, 1983), Campbell and Mankiw (1989, 1991), and that the variance of consumption growth is part of a constant drift.

${ }^{3}$ One candidate for explaining these new results would be a simple alternative rule of thumb model, where individuals consume their current income and up to their time-varying credit limit every period. There are at least three ways in which this explanation is unsatisfactory, First; unless one makes thercounter-intuitive assumption , that borrowing limits vary negatively with income, a rule of this sort would likely not be consistent with other features of the individual consumption data, such as the finding that saving is procyclical out of transitory income. Second, what happens to the consumer's intertemporal budget constraint in this case is far from clear; at least with the Hall and Mishkin - Campbell and Mankiw rule where consumption equals income, it is clear that the budget constraint is satisfied period by period. Further, many people find such an ad-hoc rule uninspiring and would rather see if there are conditions that can be placed on forward-looking behavior which rationalize the results.

${ }^{4}$ Deaton (1991) examines the time series behavior of consumption subject to a fixed borrowing constraint. Though that paper specifies no borrowing, the results of his model with stationary income trivially extend to some fixed nonzero limit.
} 
between consumption and credit, and so it raises a question about the kind of theoretical framework that can be put forward to rationalize the association between expected increases in consumption and expected increases in consumer credit. In this paper, I attempt to integrate and extend the advances made in the liquidity constraint and optimal consumption literature to provide a simple framework for studying how variation in the availability of household credit affects consumption. The model which I propose assumes rational; forward-looking consumers face a borrowing limit that is time-varying and proportional to their current income. The optimal consumption policy of an individual who faces a borrowing limit that varies with current income is quite different from the policy functions analyzed in the existing literature (e.g. Deaton, 1991) where the borrowing limit is fixed, and this modification leads, at least qualitatively, to the sort of time series properties of consumption documented here. In particular, the model produces a positive correlation between expected credit growth and consumption growth, between expected income growth and expected credit growth; and finally between consumption growth and predictable income growth, the latter by now a well known feature of the aggregate data.

Why might borrowing restrictions vary with current income? Though most of the research on liquidity constraints in the consumption literature has focused on the case of fixed borrowing restrictions, the idea that changes in credit market conditions may have real effects has precursors in recent macroeconomic literature on firm behavior. A common theme in this literature is that the financial health of firms can affect their ability to borrow, which in turn may alter their capacity to invest and produce (e.g. see Fazzari Hubbard and Petersen, 1988, Bernanke Gertler and Gilchrist, 1993). Variation in borrowers' net worth (roughly cash flow, or income, plus assets) may influence credit worthiness and therefore borrowing limitations. From a theoretical point of view, borrowing limitations may vary with income or net worth if there are informational asymmetries between borrowers and lenders. If lenders cannot costlessly acquire information about the ability of borrowers to repay, then one would expect funds provided by the lender to be limited by some observable measure of the borrower's financial health. While permanent income might be of more relevance in this regard, it seems plausible that borrowing restrictions are instead based on current income 
because the latter is more readily observable.

The rest of this paper is organized as follows. In order to motivate the theoretical model it is useful to start with the empirical results. In the next section I review the empirical model and then move on to an analysis of results from instrumental variables estimation of consumption growth. Section 3 presents the model of time-varying liquidity constraints. 3.1 outlines a baseline model of individual consumption subject to the time-varying borrowing constraint. Section 3.2 shows how variation in the borrowing limit affects the optimal consumption rule and describes the numerical solution procedure for solving the stochastic dynamic programming problem of the constrained agent. Section 3.3 discusses the solution itself. Section 4 is devoted to presenting time series simulations of the baseline model's solution. In this section, I also move away from the baseline model by relaxing the representative agent assumption and aggregating over many individuals. The time series simulations are then repeated in a model of aggregate consumption behavior. The section compares the time series behavior of consumption using the simulated data with that using the U.S. data.

To close the paper, I investigate some issues involving credit market expansion like the one-time deregulatory shift widely thought to have occurred in the 1980's in the United States and in other industrialized nations. Some have suggested that liquidity constraints have become less important over time as credit markets have evolved. Campbell and Mankiw (1991) however find no evidence of any decline in the dependence of consumption growth on predictable income growth over the post war period. To address this issue, section 4.2 simulates variation in the borrowing limit both cross sectionally and over time, and compares the results to the international studies of Campbell and Mankiw (1991) and Jappelli and Pagano (1989). Section 5 contains a summary and some concluding remarks. 


\section{Empirical Procedure}

\subsection{The empirical model}

This section reports findings pertaining to consumer credit and consumption in aggregate data. As has been customary in the macro literature, I use non-durables and services expenditures as a measure of consumption in these tests. The estimation of aggregate consumption growth and the testing of the PIH has traditionally taken one of two forms. The first is to focus on reducedform regressions in which either the growth or first difference of consumption and income make up a system, and where each are regressed on various lagged variables (e.g. Hall 1978, Flavin 1981). An alternate approach emphasizes structural estimation of aggregate consumption growth using instruments comprised primarily of the lagged variables that would otherwise be used in the reduced-form regressions (e.g. Campbell and Mankiw, 1989, 1991). An advantage in the latter approach has already been pointed out by Campbell and Mankiw (1989): if some fraction of consumption is tied to current resources (for example, if some consumers are liquidity constrained), the resulting correlation between the predictable component of any fluctuation in income growth and that of consumption growth places over-identifying restrictions on the reduced form system. As a result, the instrumental variables procedure is a more powerful test of the PIH because it estimates fewer parameters and conserves on degrees of freedom. I use the instrumental variables method here.

To make sense of the regressions I run, some background theory is useful. Suppose that permanent income consumers have iso-elastic utility: ${ }^{5}$

\footnotetext{
${ }^{5}$ The modern formulation of the PIH has quadratic utility and a constant interest rate equal to the rate of time preference. The isoelastic specification of preferences has been a popular alternative because, under special assumptions about the distribution of consumption and the real interest rate, the formulation makes clear how variation in the real interest rate should affect consumption growth. In addition, the specification is easily expresses in logs, with variables in log differences, so that there is no need to worry about non-standard distributions associated with unit roots.
} 


$$
u\left(C_{t}\right)=\frac{C_{t}^{1-\gamma}}{1-\gamma}
$$

A representative individual maximizes an infinite sum of the momentary utility functions in (1),

$$
E_{t} \Sigma_{i=0}^{\infty} \beta^{t} u\left(C_{t+i}\right)
$$

subject to a budget constraint that dictates tomorrow's assets be equal to the interest earned and principal on assets this period, plus labor income net of consumption. The resulting first order condition for optimal consumption choice is the familiar Euler equation,

$$
E_{t}\left[\beta R_{t+1}\left(C_{t+1} / C_{t}\right)^{-\gamma}\right]=1
$$

Carroll (1991) and Carroll and Kimball (1995) have recently shown that, with iso-elastic utility, precautionary motives imply that the variance of consumption is endogenous, indicating the growth in consumption is not unpredictable. One special case that has nevertheless received much consideration elsewhere in the literature assumes that the variance of consumption is approximately constant. If in addition one assumes that the real interest rate, $R_{t+1}$, is constant and equal to the rate of time preference, the loglinear version of (3) implies log consumption follows a martingale process, so that the growth in consumption is unpredictable. That is (with lower case letters denoting logs),

$$
\Delta c_{t}=\mu+\epsilon_{t}
$$


where $\epsilon$ is the innovation to permanent income.

Before considering the implications of stochastic interest rates, it is useful to introduce some notational conventions concerning the timing assumption of measured debt. Debt can be measured at the begining of the period or the end of the period. The timing convention I will use is that $D_{t}$ is beginning of period debt. That is, $D_{t+1}$ is what accrues when $C_{t}$ is greater than $Y_{t}$, so that $D_{t+1}$ and debt growth, denoted $\Delta d_{t+1}$, are quantities entirely determined by variables in period t. The rest of the paper uses this timing convention by denoting predictable debt growth as $E_{t-1} \Delta d_{t+1}$.

In the iso-elastic formulation, an extensively used alternative to (4) which allows for time-varying interest rates, is a highly stylized model in which the agent can borrow and lend at the same rate, $r_{t}$, and a generalization of the Euler equation which assumes asset returns and consumption are jointly lognormal and homoskedastic. With these assumptions equation (3) can be written in logs,

$$
E_{t-1} \Delta c_{t}=\mu^{\star}+\sigma E_{t-1} r_{t}
$$

where $r_{t}$ denotes the time-varying interest rate, $\sigma \equiv 1 / \gamma, \mu^{\star}$ is a constant, and lower case letters refer to variables in logs. ${ }^{6}$

Equation (5) shows that the expected real interest rate can be anticipated to affect consumption growth if some consumers are forward-looking and if they have some willingness to substitute consumption over time. Other researchers have however repeatedly demonstrated the importance of, not the real interest rate, but either lagged or predictable income growth in determining consumption growth (Flavin, 1981, Campbell and Mankiw 1989, 1991, Deaton, 1992): For example; Campbell and Mankiw (1989) add expected income growth to the equation:

$$
\Delta c_{t}=\mu+\lambda E_{t-1} \Delta y_{t}+\theta E_{t-1} r_{t}+\epsilon_{t}
$$

\footnotetext{
${ }^{6}$ Again, $\mu^{\star}$ will not be a constant unless the joint distribution of asset returns and consumption is assumed to be approximately homoskedastic.
} 
where $\mu=(1-\lambda) \mu^{\star}, \theta=(1-\lambda) \sigma$, and the error term, $\epsilon_{t}$, is orthogonal to all variables known at time t-1 or before. They find that predictable income growth has considerable explanatory power not captured by the expected real interest rate. ${ }^{7}$

In order to control for variables known to be important in determining consumption growth either empirically and theoretically, I specify the most general equation to be estimated as,

$$
\Delta c_{t}=\mu+\lambda E_{t-1} \Delta y_{t}+\theta E_{t-1} r_{t}+\alpha E_{t-1} \Delta d_{t+1}+\epsilon_{t}
$$

The examination of consumption and credit in the next section begins by estimating consumption growth in (7) as a function of $E_{t-1} \Delta d_{t+1}$ alone, and then moves on to ask whether predictable credit growth has any additional explanatory power once $E_{t-1} \Delta y_{t}$ and $E_{t-1} r_{t}$ are controlled for.

\subsection{Estimation}

The model is estimated using U.S. quarterly times series data ${ }^{8} \cdot Y_{t}$ is measured as disposablepersonal income per capita in 1987 dollars, $C_{t}$ is consumption of non-durables and services, per capita in 1987 dollars, and $r_{t}$ is obtained by averaging the three month $t$-bill rate over the quarter. ${ }^{9}$ The price index used to convert to real rates is the consumer price index, and I assume a marginal tax rate on nominal interest of 30 percent.

The credit data is consumer installment credit collected by the Board of Governors of the Federal Reserve. These are short and intermediate term loans, not secured by real estate, and scheduled to be repaid in two or more installments. The series contains credit-used for both durables and nondurables with automobile and credit card debt making up the largest fractions. Because the right

\footnotetext{
${ }^{7}$ Campbell and Mankiw interpret their results as supporting rule of thumb consumption and $\lambda$ as approximating the fraction of income accruing to agents who consume their current income in every period.

${ }^{8}$ All of the series other than the installment credit is obtained from the Citibase data bank. Consumer installment credit is obtained from the Federal Reserve Board's G19 statistical release.

${ }^{9}$ Since data on personal disposable income are more readily available than data on labor income, I use the former as a proxy for the latter. This usage has been justified in previous work by noting that the two series vary similarly.
} 
where $\mu=(1-\lambda) \mu^{\star}, \theta=(1-\lambda) \sigma$, and the error term, $\epsilon_{t}$, is orthogonal to all variables known at time t-1 or before. They find that predictable income growth has considerable explanatory power not captured by the expected real interest rate. ${ }^{7}$

In order to control for variables known to be important in determining consumption growth either empirically and theoretically, I specify the most general equation to be estimated as, - - w

$$
\Delta c_{t}=\mu+\lambda E_{t-1} \Delta y_{t}+\theta E_{t-1} r_{t}+\alpha E_{t-1} \Delta d_{t+1}+\epsilon_{t}
$$

The examination of consumption and credit in the next section begins by estimating consumption growth in (7) as a function of $E_{t-1} \Delta d_{t+1}$ alone, and then moves on to ask whether predictable credit growth has any additional explanatory power once $E_{t-1} \Delta y_{t}$ and $E_{t-1} r_{t}$ are controlled for.

\subsection{Estimation}

The model is estimated using U.S. quarterly times series $\operatorname{data}^{8} \cdot Y_{t}$ is measured as disposable personal income per capita in 1987 dollars, $C_{t}$ is consumption of non-durables and services, per capita in 1987 dollars, and $r_{t}$ is obtained by averaging the three month t-bill rate over the quarter. ${ }^{9}$ The price index used to convert to real rates is the consumer price index, and I assume a marginal tax rate on nominal interest of 30 percent.

The credit data is consumer installment credit collected by the Board of Governors of the Federal Reserve. These are short and intermediate term loans, not secured by real estate, and scheduled to be repaid in two or more installments. The series contains credit used for both durables and nondurables with automobile and credit card debt making up the largest fractions. Because the right

\footnotetext{
${ }^{7}$ Campbell and Mankiw interpret their results as supporting rule of thumb consumption and $\lambda$ as approximating the fraction of income accruing to agents who consume their current income in every period.

${ }^{8}$ All of the series other than the installment credit is obtained from the Citibase data bank. Consumer installment credit is obtained from the Federal Reserve Board's G19 statistical release.

${ }^{9}$ Since data on personal disposable income are more readily available than data on labor income, I use the former as a proxy for the latter. This usage has been justified in previous work by noting that the two series vary similarly.
} 
hand side variable in (7) is consumption of nondurable and services, some may find it more intuitive to use revolving credit (primarily credit card debt) as the explanatory variable. Of course, revolving credit is also used for durable goods purchases, so that it becomes impossible to disaggregate credit into that which is used exclusively to pay for durables and that which is used to purchase nondurables and services. In the next section I argue that disaggregating consumption and credit into categories that perfectly "match" would not be particularly meaningful even if one could do it. This is because the resources that additional credit provides are fungible. What matters for the constrained individual who consumes all categories of consumption is the overall availability of credit, not what type of good the credit is ear-marked for.

Still, for the sake of completeness it seems useful to examine the way consumption responds to both total consumer installment credit and the revolving component of it. This raises an issue about where to start the sample. The total consumer installment credit series begins in 1949. However, it was not until the late 1970's that revolving credit came into extensive use. The explosion in credit card use came in the 1980's and is thought to be strongly related to a 1978 supreme court ruling which relaxed and removed interest rate ceilings on bank cards and allowed issuers to charge a variety of fees for them. This deregulatory shift not only increased the amount of credit available to those who already had access to it, but it greatly widened the availability of credit to others, including young consumers and those with low incomes (Staten and Johnson, 1995). As a result, I estimate consumption growth as a function of expected installment credit growth over the period 1953:1 to $1993: 1$ and as a function of revolving credit growth for the period since 1978:1. $D_{t}$ is credit, per capita, in 1987 dollars.

winally, as already discussed, instruments are needed to estimate (7). The conditional expected values that make up the explanatory variables are not observable. Although the actual values might be good proxies, OLS cannot be used since the error term would then be correlated with the explanatory variables on the right hand side. To correct for this, the standard error in variables procedure calls for instrumental variables estimation. The instruments used here are lagged consumption growth, lagged income growth, and the "error correction" term, the lagged log con- 
sumption to income ratio. In addition, when real interest rates are controlled for, lagged values of that variable are also used as instruments. I also add lagged credit growth to the set of possible instruments. ${ }^{10}$ Due to well known problems of time averaging in quarterly data, all instruments are lagged at least twice.

Tables $1 \mathrm{a}$ and $1 \mathrm{~b}$ present results. Table $1 \mathrm{a}$ presents the first and second stage results using total installment credit. Each column corresponds to a particular set of instruments which are described below the table and are various combinations of the lagged variables. Table $1 \mathrm{~b}$ does the same using revolving credit.

The first panel in each table reports the point estimates for $\lambda$, the coefficient on $E_{t-1} \Delta y_{t} ; \theta$, the coefficient on $E_{t-1} r_{t}$; and $\alpha$, the coefficient on $E_{t-1} \Delta d_{t+1}$, with $t$ statistics in parenthesis. The second panel gives the adjusted $R^{2}$ statistic from OLS first stage regressions of $\Delta y_{t}$ and $\Delta d_{t+1}$, respectively, on the instruments. ${ }^{11}$ The final row of the second panel gives results from a test of over-identifying restrictions. ${ }^{12}$

\subsection{Results}

Consider the results in Table $1 \mathrm{a}$, where total installment credit is used as a measure of consumer debt. In the first stage regressions, all of the instrument sets have significant predictive power for credit growth. As the last panel of Table 1 indicates, they are jointly significant at very high significance levels. The joint marginal significance level for the instruments is always less than 0.001 in the first stage regression of credit growth on the instruments. It is interesting that these variables, often used to forecast income growth, seem to have nsiderably more predictive power for consumer credit growth than they do for income growth. Still, there are two instruments sets

\footnotetext{
${ }^{10} \mathrm{~A}$ constant term is always included as both an instrument and a regressor though it is not reported in the tables.

${ }^{11}$ Not reported are the first stage results for the expected real t-bill rate, which are well forecast by its own lagged values as has been documented elsewhere, e.g. Campbell and Mankiw, 1989.

${ }^{12} \mathrm{An}$ LM test statistic is formed by regressing the residual from the IV regression on the instruments. Taking $T$ times $R^{2}$ from this regression, where $T$ is the sample size, produces a test statistic that is distributed $\chi^{2}$ with $K-3$ degrees of freedom, where $K$ is the number of instruments. The corresponding number in the table is the $T * R^{2}$ statistic for the OLS regression of the IV residual on the instruments.
} 
with joint significance for income growth at better than the 5 percent level, and two with joint significance at better than the 7 percent level, ranges that other authors have considered acceptable (e.g. Campbell and Mankiw, 1989, 1991), but which undoubtedly deserves some degree of caution. On the other hand, the strong forecasting power of the instruments for credit growth indicates the second stage results using this variable as a regressor are much more reliable. ${ }^{13}$

The row labeled "Test of Restrictions" shows that there is no evidence against the over identifying restrictions imposed by the model; the test results do not reject the null hypothesis that the overidentifying restrictions are true for any set of instruments considered.

Table 1a also shows there is no evidence that the ex-ante real interest rate is associated with the growth rate of consumption; the coefficient on the real interest rate is always significantly less than its standard error. ${ }^{14}$ In addition, the results corroborate previous findings that predictable income growth has significant explanatory power in determining consumption growth when it is the only regressor or when just the expected real interest rate is controlled for. In each case, the point estimates of about 0.4 for the coefficient on expected income growth are roughly of the same magnitude as that reported in the Campbell and Mankiw investigation.

When consumption growth is estimated as a function of expected credit growth alone, the point estimates of $\alpha$, the coefficient on expected consumer credit growth, are about 0.1 in Table 1a, rejecting the permanent income hypothesis that $\alpha=0$ at the 0.2 percent level. Finally, controlling for expected income growth and the ex ante real interest rate, predictable credit growth remains

\footnotetext{
${ }^{13}$ Recently, some have suggested that a better measure of instrument relevance in multivariate linear models is not the simple adjusted $R$ squared form regressing the explanatory variable on the instruments, but an alternative measure sometimes called the "partial"R squared (e.g. Shea, 1993). I computed this measure for a variety of instrument sets considered here and found that the degree of relevance for each explanatory variable was very similar to that indicated by the conventional measure. For example, when the instruments are lags two through four of consumption growth, credit growth, income growth, the real interest rate and lag two of the log consumption to income ratio, the partial $R$ squared measure for income growth, debt growth and the real interest rate is $0.09,0.42$, and 0.44 , respectively (compare to Table $1 \mathrm{la}$ ).

${ }^{14}$ One possibility is that I have used the "wrong" interest rate. The stylized model which suggests that consumers can borrow and lend at the same rate is clearly at odds with the facts. Of course, for (5) to hold, rates need not be actually equal but only within a constant of one another. If instead there is variation in the spread between various rates the results could be sensitive to which rate is used. I tried using two borrowing rates instead of the t-bill rate (the average prime lending rate and average credit card rate charged by commercial banks) and found no appreciable difference in the results.
} 
a statistically significant determinant of consumption growth in every instrument set considered. Interestingly, the explanatory power of predictable income growth seems to be substantially compromised by the inclusion of expected credit growth as an additional explanatory variable; of the four regressions run with both variables included, predictable income growth remains a significant explanatory variable in only one, and this required using additional lags of the variables as instruments. ${ }^{15}$ This finding warrants further investigation.

The results in Table $1 \mathrm{~b}$, where revolving credit is used, are similar. In particular,.. expected credit growth is a significant explanatory variable in each regression on consumption growth, and is strongly forecast by the instrument sets. ${ }^{16}$ In this Table I also report the results using the prime lending rate rather than the three month t-bill rate, since much of bank card debt is tied to an adjustable index, usually the prime rate. ${ }^{17}$ In these regressions, the prime rate has more explanatory power than the t-bill rate, but is still not significant at the 5 percent level, and its inclusion does not qualitatively influence the coefficients on expected credit growth or expected income growth. ${ }^{18}$

Finally, in regressions using both total installment credit and revolving credit I experimented with adding two dummy variables with little impact on the results: 1975:2 (social security and income-tax rebate) and 1980:2 (credit controls). The former controls for periods in which there were large swings in tax policy which distorted the disposable income data but not the labor income data, as listed in Carroll, Furher, and Wilcox (1994).

\section{The Link to Theory}

\footnotetext{
${ }^{15}$ Second stage regression results at annual frequencies are similar to those reported in Table 1 at quarterly frequencies, and in particular, expected credit growth remains a strong predictor of consumption growth. The first stage correlations are more difficult to replicate however; both income growth and credit growth appear to be much less correlated with lagged variables at annual frequencies.

1...160ne difference from Table $1 \mathrm{a}$ is that the instrument sets for expected income growth are very weak predictors over this smaller sample period regardless of what combination of instruments is used.

${ }^{17}$ Approximately $70 \%$ is tied to such rates, according to Staten and Johnson, 1995.

${ }^{18}$ The Federal Reserve Bulletin statistical release G19 does not report revolving credit prior to 1968, first quarter. At that time, total revolving credit was quite small and less than $2 \%$ of total installment credit; in 1985 it made up about $24 \%$, and by 1994 was the greatest fraction of total at $37 \%$. The strong relationship between consumption and credit that is reported in Table 1a for total installment credit, and Table $1 \mathrm{~b}$ for post 1978 revolving credit, is not evident when revolving credit is used post 1968. I suspect this is due to the fact that revolving credit did not come into wide use until the 1980's, and in particular was not yet available to large classes of consumers such as younger, lower income, less wealthy consumers who may be more likely to be credit constrained.
} 
The instrumental variables tests in this section show that consumption growth is correlated with predictable consumption growth. As already discussed, this finding is not readily explained by existing theories of consumer behavior. One possible reaction to these findings is that preferences are more complicated than those specified in the models discussed above. For example, non-time-separability between durables and non-durables would imply that non-durable consumption growth should be related to the growth in durables consumption. If so, expected installment credit could simply be proxying for expected durables consumption in equation (7). Further calculations (not reported) showed that, unlike expected credit growth, expected growth in durables consumption is not significantly correlated with the growth in non-durables and services expenditure, once predictable income growth and the expected real interest rate are controlled for. This result is consistent with the findings of Campbell and Mankiw (1990) who report no evidence for this type of non-separability. I rule out this interpretation of the data and instead present a liquidity constraint model with time- varying borrowing restrictions.

The next section considers relatively impatient consumers who are therefore motivated to borrow and trade off consumption tomorrow for consumption today, but who are faced with a borrowing limitation that, rather than being fixed, is proportional to their current.income. This extension of the more traditional modeling of constrained consumer behavior immediately captures one noteworthy aspect of the data: the positive correlation between instrumental variables forecasts of income growth and those of credit growth. The primary goal is to provide a framework for thinking about the observed high frequency correlation between the growth in non-durables and services consumption and predictable credit growth.

I do not address the apparent secular change (or at least thewery low frequency movements) in the debt to income ratio displayed in Figure 1, which is difficult to explain in models with constant, balanced growth in the steady state. In addition, it might be useful to explore theoretically more complex relationships between the credit limit and income which maintain predictability in the growth of the credit limit. Unfortunately, modifications in this direction generally call for the addition of at least two state variables over what is required by the model presented in the next 
section. The equations representing optimal, forward-looking consumption behavior subject to inequality constraints are highly non-linear, and short of switching to a super computer solution techniques become computationally intractable when there are three or more state variables. For

"this reason, I view the simpler formulation that follows, where borrowing limitations are proportional to income, as a natural starting place.

\section{A Model of Time-varying Liquidity Constraints}

\subsection{The individual's decision problem: a baseline model}

The strategy presented in thisection is to derive the policy function for consumption of an optimizing individual who faces a borrowing constraint that is tied to income, within the standard framework of intertemporal utility maximization. The purpose of this exercise is to trace out the dynamic properties of consumption and credit growth in a model with time-varying liquidity constraints.

Two preliminary modeling issues arise. The first is that some credit, as measured by the available data series, is used for a category of consumption (e.g. durables) that is not reflected in the left hand side variable of the regression (7). A second issue is how the evolution of a durables stock might interact with liquidity constraints to influence the behavior of the growth in non-durables and services expenditures (even when utility is additively separable between the two types of goods). The first issue concerns the fungibility of resources and has nothing to do with durable goods per se, while the second issue has to do with tracing out the effects of an additional state variable which is the evolving durables stock.

The first issue is resolved by noting that expenditures for all goods enter the budget constraint symmetrically, so that it doesn't matter which good the credit is designated for. If one artificially splits expenditure on non-durables and services consumption at time $t$ into two categories, $W_{t}$ and 
$Z_{t}$, it is simple to see that the consumer's optimization problem is the same regardless of which category of consumption the credit is earmarked for. For example, if the credit is to be used for $Z$, then the consumer solves:

$$
E_{t}\left(\Sigma_{i=0}^{\infty} \beta^{i}\left(\frac{W_{t+i}^{1-\gamma}}{1-\gamma}+\frac{Z_{t+i}^{1-\gamma}}{1-\gamma}\right)\right) \quad \beta<1
$$

subject to a debt evolution constraint:

$$
D_{t+1}=(1+r)\left(D_{t}+Z_{t}-\left(Y_{t}-W_{t}\right)\right){ }^{19}
$$

where $Y_{t}$ is labor income, $D_{t}$ is real debt, and $\mathrm{r}$ is the real interest rate. Equation (9) says that debt tomorrow is equal to the interest and principal owed on outstanding debt today, plus purchases of the good $Z_{t}$ less the resources remaining with which to pay down obligations, equal to income, $Y_{t}$, net of $W_{t}$. If instead credit was used for the purchase of $W_{t}$, then the consumer's problem is again to solve (8), subject to a budget constraint. which can be trivially re-written as

$$
D_{t+1}=(1+r)\left(D_{t}+W_{t}-\left(Y_{t}-Z_{t}\right)\right) .
$$

The consumer's problem is the same whether the debt is to be used for $W_{t}$, for $Z_{t}$, or for the sum of the two, $C_{t} \equiv W_{t}+Z_{t}$. This makes the simple point that consumer credit is fungible $;$ all expenditures enter the budget constraint symmetrically, and as long as the consumer receives utility from both goods, credit for one good simply frees up income for the other. Therefore variation in the amount of overall credit available will directly affect expenditure on both goods for a constrained consumer.

\footnotetext{
${ }^{19}$ Without loss of generality, the relative price of $\mathrm{Z}$ in terms of $\mathrm{W}$ is normalized to 1 .
} 
The second issue is much harder to address. The solution to this model must be sought numerically which places limitations on how complex the set-up can be. The problem becomes computationally intractable with the addition of a fully evolving durables stock to the problem of solving för an actual consumption function subject to time-varying borrowing limits. ${ }^{20}$ In what follows I choose to greatly simplify the problem by assuming that credit for durables affects the consumption of non-durables and services because the two forms of expenditure affect the budget constraint symmetrically, as discussed above.. In modeling the determination of the latter I abstract from fully evolving durables consumption and write the problem so that all expenditure is collapsed into one non-durables and services good, $C_{t}$. This is tantamount to assuming that durable goods completely depreciate within the period. Obviously this leaves open the question of how durables evolution would interact with time-varying liquidity constraints in this setting, an issue I leave to further research. The rationalization is computational manageability not realism.

I assume that individuals maximize the infinite sum of instantaneous utility functions in (2) with $\beta=(1+\delta)^{-1}$, where $\delta$ is the strictly positive rate of time preference. This specification yields convex marginal utility, so that unlike the PIH which incorporates certainty equivalence with quadratic utility, there is a precautionary motive for saving. The consumer can take on debt, which I assume is one-period and evolves according to

$$
D_{t+1}=(1+r)\left(D_{t}+C_{t}-Y_{t}\right)
$$

where $r$ is the real interest rate at which consumers can borrow, which I treat as fixed and known. ${ }^{21}$

\footnotetext{
${ }^{20}$ The problem becomes computationally even more difficult if one allows variation in the relative price of durables in terms of non-durables.

${ }^{21}$ Unless $r$ is specified as the rate at which consumers can borrow and $D$ restricted to be positive, then (11) specifies the evolution of net debt (net of assets), which creates a wedge between the theory and the credit series in the data. In reality, consumer credit can not be described as the negative of most of the assets held in the U.S. economy and so assets and debt are distinct stocks. A challenging direction for future research would be to include the behavior of individuals who choose to hold both consumer credit and positive assets in many periods of their life time, as well as for the presence of large, illiquid assets, though in this paper I abstract from both of these possibilities and focus on the consumer who just runs up debt. Therefore to make (11) consistent with the definition of debt in the data, I restrict $D$ to be non-negative. This constraint never binds however, because I assume that agents are sufficiently
} 
The only source of uncertainty comes through labor income which I assume follows an exogenous stochastic process. This process is specified so that $(\log )$ income is the sum of a white noise transitory component, and a random walk with drift "permanent" component. That is in levels, $Y_{t}=Y_{1, t} Y_{2, t}$, or in logs, $y_{t}=y_{1, t}+y_{2, t}$, where $y_{1, t}$ is a random walk with positive drift $g$, and $y_{2, t}$ is white noise. This representation is equivalent to the $\log$ first difference of income being a moving average, $\ldots$

$$
\Delta \ln y_{t}=g+\eta_{t}-\psi \eta_{t-1}
$$

I also suppose the agent is impatient in the sense that borrowing is part of the optimal plan. In models without income uncertainty and where there is no deterministic income growth, impatience arises when the rate of time preference exceeds the rate of return on deferred consumption. In models of liquidity constraints, however, when there are precautionary saving motives and constant income growth at some rate $g$, this condition needs to be generalized. Deaton (1991) gives the appropriate generalization which I reference below for the case where $\Delta y_{t}$ is $N\left(g, \sigma^{2}\right)$ :

$$
\gamma^{-1}(r-\delta)+\gamma \sigma^{2} / 2<g
$$

Though $\delta>r$ together with non-negative income growth, $\mathrm{g}$, is a sufficient condition for (13) to hold, higher rates of income growth, as long as they are not too variable, make the condition unnecessary. Even consumers who discount the future very little will still want to consume today out of tomorrow's predictably higher income, and less variation in the income draw reduces the need for precautionary saving.

Instead of being fixed (as is conventional), the consumer's borrowing limitation is assumed to be proportional to current income,

impatient so that they will always choose to borrow a non-negative amount in every period. 


$$
D_{t+1} \leq \bar{D}_{t+1} \quad \equiv \quad \frac{1}{\omega} Y_{t}, \quad \omega>1,
$$

where $\omega$ is fixed and known. Because the evolution of debt given in equation (11) specifies that $D_{t}$ is beginning of period debt, the timing assumption designates that the upper limit on credit at time $t$ is proportional to income at time t-1. In $\operatorname{logs}$, the constraint (14) is $\vec{d}_{t+1}=y_{t}-\ln \omega$ so that the growth rate of the credit constraint is, $\Delta \bar{d}_{t+1}=\Delta y_{t}=g+\eta_{t}-\psi \eta_{t-1}$ and the log income to credit limit ratio is $y_{t+1}-\bar{d}_{t+1}=\Delta y_{t+1}+\ln \omega$.

\subsection{Numerical solution procedure}

As there is no known analytical solution to the model presented above, I seek a numerical solution to the optimal policy functions. Deaton (1991) outlines a nice way to set up the problem when borrowing restrictions are fixed, and I follow a similar procedure here to solve the problem with time-varying constraints. Another useful reference for numerical techniques is Judd (1991).

Denote the instantaneous marginal utility of consumption as $v\left(c_{t}\right)$, i.e.

$$
v\left(C_{t}\right) \equiv u^{\prime}\left(C_{t}\right),
$$

where I assume $u^{\prime}(\cdot)=C_{t}^{-\gamma}$, as given in (1). Also, define the consumer's upper spending limit at time $t$ as $X_{t}$ (referred to from here on as current resources for short). From (11) with $D_{t+1}=\bar{D}_{t+1}$, we have

$$
X_{t} \equiv \frac{\bar{D}_{t+1}-D_{t}(1+r)}{(1+r)}+Y_{t}
$$


Equation (16) simply says the most that can be spent on consumption in period $t$ is all of income, and up to the credit limit less the interest and principal owed on outstanding debt. ${ }^{22}$ With (16), the first order condition which imposes the constraint (14) can be written as the following Euler equation

$$
C_{t}^{-\gamma}=\max \left[X_{t}^{-\gamma}, \beta^{\star} E_{t} C_{t+1}^{-\gamma}\right]
$$

where $\beta^{\star}=(1+r) /(1+\delta)$, and $\beta^{\star}<1$ since $r<\delta$. Since $X_{t}$ is the most that can be consumed, marginal utility can never be less than $X_{t}^{-\gamma}$. Without the time-varying borrowing limit imposed by (14), (17) collapses to the usual Euler equation where the first element in brackets is eliminated.

Nonstationary income will result in nonstationary processes for consumption and household debt. In order to define a stationary policy function over these variables, they must first be transformed into stationary ratios of variables. Define $z_{t+1}$ as

$$
z_{t+1} \equiv Y_{t+1} / Y_{t}=\exp \left(g+\eta_{t+1}-\psi \eta_{t}\right)
$$

Using this notation, the Euler equation (18) can be written as

$$
\theta_{t}^{-\gamma}=\max \left[w_{t}^{-\gamma}, \beta^{\star} E_{t} z_{t+1}^{-\gamma} \theta_{t+1}^{-\gamma}\right]
$$

where, $\theta_{t} \equiv C_{t} / Y_{t}, w_{t} \equiv X_{t} / Y_{t}$.

To see how this type of borrowing limit changes the optimal consumption policy, one must

\footnotetext{
${ }^{22}$ Note that (16) will never be negative. This is because, with isoelastic preferences, there is an infinite penalty for zero consumption. The consumer knows the distribution of income and so never chooses the endogenous variable $D_{t}$ to be so large that $X_{t}$ is negative.
} 
consider how it will influence the evolution of resources. Given (11), the resource to income ratio, $w$, evolves according to

$$
w_{t+1}=(1+r)\left(w_{t}-\theta_{t}\right) z_{t+1}^{-1}+\frac{\bar{D}_{t+2}-\bar{D}_{t+1}(1+r)}{(1+r) Y_{t+1}}+1
$$

Notice that the time-varying borrowing limit, $\vec{D}_{t}$, directly influences the evolution of resources through the second to last term in (20) which would disappear in this model with fixed liquidity constraints where borrowing is prohibited.

In order for the consumer's problem to be well defined, $w$ must evolve in a stationary way. Here, the assumption that the credit limit is tied to current income is crucial. To see why, divide the numerator and denominator of the second to last term in (12) by $\bar{D}_{t+1}$ and use the fact that $\bar{D}_{t+1}$ is proportional to income in (14) so that (20) becomes

$$
w_{t+1}=(1+r)\left(w_{t}-\theta_{t}\right) z_{t+1}^{-1}+\frac{\exp \left(\eta_{t+1}-\psi \eta_{t}+g\right)-(1+r)}{(1+r) \exp \left(\eta_{t+1}-\psi \eta_{t}+g+\ln \omega\right)}+1
$$

Equation (21) shows that $w_{t+1}$ consists only of white noise random shocks and stationary ratios of variables. Note however, as can be seen from (20), when income is non-stationary the problem is not well defined for fixed borrowing restrictions other than those where the limit is zero because in that case the debt-limit to income ratio is no longer stationary.

$\cdots$ Given the evolution of the stationary resource ratio, $w$, it is nowspossible to look for a stationary solution to the recursive problem in (19) in which the consumption to income ratio, $\theta$, is a function of the state variables in the model. One such state variable is $w_{t}$ itself, since its evolution can be used to predict the expected marginal utility of consumption tomorrow. However, since income growth (13) is serially correlated, the expected marginal utility of tomorrow's consumption will also depend on $\eta_{t}$, the component of income growth known at time t. Therefore consumers will also 
condition on the known value of $\eta_{t}$ when forming expectations about their income and borrowing limitation in period $t+1 . .^{23}$ As a result, the optimal policy function will depend not only on $w$, but also on the transitory i.i.d. shock $\eta_{t}: \theta=f\left(w_{t}, \eta_{t}\right)$. Define $p\left(\theta_{t}, \eta_{t}\right)=v\left[f\left(w_{t}, \eta_{t}\right)\right]=f\left(w_{t}, \eta_{t}\right)^{-\gamma}$. Making these substitutions in (19) gives

$$
\begin{array}{r}
p\left(w_{t}, \eta_{t}\right)=\max \left[v\left(w_{t}\right), \beta^{\star} E_{t} z_{t+1}^{-\gamma} p\left\{1+z_{t+1}^{-1}(1+r)\left(w_{t}-v^{-1} p\left(w_{t}, \eta_{t}\right)\right)\right.\right. \\
\left.\left.+\frac{\exp \left(\eta_{t+1}-\psi \eta_{t}+g\right)-(1+r)}{(1+r) \exp \left(\eta_{t+1}-\psi \eta_{t}+g+\ln \omega\right)}, \eta_{t+1}\right\}\right]
\end{array}
$$

where $z_{t+1}$ is given in (18) and the conditional expectation in (22) is taken with respect to the i.i.d. variable $\eta_{t+1}$.

Equation (22) shows how the optimal policy is directly influenced by the presence of time-varying borrowing constraints. Again, this is evident from the third term in curly brackets which would be absent altogether in the case of fixed liquidity constraints which prohibit borrowing. Even though the conditional expectation is taken with respect to the current income shock, the relationship between the optimal consumption policy and innovations in current income is substantially, complicated by a borrowing restriction that varies with current income. Given that (22) consists of stationary, i.i.d. variables, I now look for a unique, optimum policy function and apply standard numerical dynamic programming methods to solve for the policy function $p$, and hence $f .{ }^{24}$

I assume the support of $z$ is finite, and that there is a strictly positive floor on income (ergo, a strictly positive floor on the credit limit), forcing $z$ to be bounded away from zero, $z>z_{0}=0$. This circumvents the voluntary no-borrowing result in models like those of Carroll (1991). In that

\footnotetext{
${ }^{23}$ It is a well known, (see Deaton 1991 and Zeldes, 1989) but important feature of these types of models that the expectation also takes into account the likelihood of being liquidity constrained tomorrow; in periods when borrowing limits are not binding, consumption behavior will still deviate from that of an individual who could never possibly be constrained because (14) is not imposed.

${ }^{24}$ Deaton and Laroque (1992) have already demonstrated that if (13) holds, a unique optimum policy will exist for the less complex type of recursive equation in (22) that exists for the case of a fixed borrowing limitation that prohibits borrowing.
} 
context, there is always some positive probability that the consumer will be left with no income in the next period. As a result, it is suboptimal for the agent not to hold strictly positive assets in order to avoid the potential for zero consumption and infinite marginal utility. In this model, I rule out the possibility of receiving, not- only a non-positive income draw, but also a non-positive borrowing limit. Therefore, the consumer always expects to have some resources to draw upon no matter how bad times are. This leaves room for borrowing, though the consumer here will never optimally borrow so much that there is a possibility (given the known distribution of income) for tomorrow's resources to fall to zero after payments on outstanding debt are made.

The expectational integral in (19) could in principle be solved using Simpson's rule or a similar approximation. However, this turns out to be computationally cumbersome since the policy function already has to be evaluated over two state variables. To avoid this difficulty, I instead make a discrete approximation of an underlying normal distribution for $\eta$ with mean zero and constant variance $\sigma^{2}$ which preserves the income floor. The income innovation then takes on $m$ discrete values with equal transition probabilities, $\pi_{j}$. This approach is similar to that suggested in Tauchen (1986) and is also presented in detail in Deaton (1991). I refer the reader to those articles and only outline the method below.

Suppose that $\eta$ is normally distributed, $N\left(0, \sigma^{2}\right)$. First, $m$ points are chosen so that successive areas under the standard normal between each of these points are equal to $1 / m$. Then the $m$ conditional means within each of these intervals are chosen as the $m$ equiprobable values of a discrete process that approximates $N(0,1)$. Each of these values are then multiplied by $\sigma$ so that $\Delta y_{t}$ in (13) is replaced by a discrete, first order Markov process consisting of innovations $\eta$ that approximate $N\left(0, \sigma^{2}\right)$. Optimizing agents will take expectations over the $m$ discrete values of $\eta_{t+1}$. Since there are $m$ possible values of $\eta_{t+1}$ there are $m$ possible "states upon which to condition expectations. Label the $m$ states $i=1, \ldots, m$. This gives $m$ functions, $p(w, i)$, defined by the set of functional equations, 


$$
p(w, i)=\max \left[v(w), \beta^{\star} \sum_{j} \pi_{j} \rho_{i j}^{\gamma} p\left\{\left[1+\rho_{i j}(1+r)\left(w-v^{-1} p(w, i)+\zeta_{i j}\right], j\right\}\right]\right.
$$

where

$$
\begin{gathered}
\rho_{i j} \equiv \exp \left(-\eta_{j}+\psi \eta_{i}-g\right) \\
\zeta_{i j} \equiv \frac{\exp \left(\eta_{j}-\psi \eta_{i}+g\right)-(1+r)}{(1+r) \exp \left(\eta_{j}-\psi \eta_{i}+g+\ln \omega\right)} .
\end{gathered}
$$

Equation (23) simply rewrites (22) using the income process in (12), and the credit constraint (14). A numerical procedure can now be applied to the stochastic dynamic program (23) giving $m$ optimal policy functions $f\left(w_{t}, \eta_{t}\right)$ found by recursion. A brief description of this recursion is given in the appendix.

\subsection{The optimal policy}

To'assign values to the model's underlying parameters, I start by utilizing MaCurdy's 1982 analysis of the PSID data. His estimate of the income process given in (12) indicates $\psi$ is 0.44 . I also set $r=0.03, g=0.02$, and $\gamma=2 .{ }^{25}$ The values of $\sigma, \omega$, and $\delta$ are adjusted in several different cases described below. I take $m$, the number of discrete states, to be 10 , leaving 10 policy functions, computed for the 10 point discrete approximation described above.

Figure 2 shows the set of optimal policy functions, where $\theta_{t}$, the consumption to income ratio, is plotted against $w_{t}=X_{t} / Y_{t}$, the resource to income ratio. To illustrate the general flavor of the solution, Figure 2 contrasts the policy function in two cases of uncertainty: $\sigma=0.05$ (Figure 2a) and $\sigma=.15$ (Figure 2b). $\delta$ was set to 0.05 and $\omega=5$ in both examples.

\footnotetext{
${ }^{25}$ Note in the steady state defined by $\eta_{t}=0 \forall t$ and where the debt to income ratio is constant, the presumption that $r>g$ rules out Ponzi games.
} 
The general shape of the policy function is similar to that obtained in models of fixed borrowing limits like Deaton (1991). An important difference in this model, however, is that $w$ depends on the time-varying credit limit as well as on current income and accumulated debt. The nature of the solution in both cases is simple; when resources are sufficiently low, the agent consumes everything. Otherwise, the relationship between consumption and current resources flattens out. In all states, when total resources fall below some minimum, the marginal value of these resources today is higher than the marginal value of consumption tomorrow, and the individual simply consumes them, eating all of current income and borrowing up to the current credit limit net of the interest and principle owed on previously accrued debt. Over this region of resources, the policy function is a 45 degree line.

On the other hand, when resources are sufficiently high, the marginal value of current resources is less than that of consumption tomorrow, the consumption decision is not constrained by the period's resource draw, and borrowing falls short of the current credit limit. In this region the consumer smooths out transitory changes in income by accumulating and decumulating debt, a response made possible by the existence of a positive floor on the credit limit.

A high innovation in $\eta_{t}$ implies low income growth next period, so that the lowest income state corresponds to the highest branch, and the highest income state corresponds to the lowest branch in both figures. The intermediate states fall in ascending order (from the top down) in between these two. When income is low today, it is expected to be higher tomorrow, leading to an increase in the consumption-income ratio, so that consumption out of any given level of resources will be higher. Saving is procyclical out of transitory income.

Transitory swings in income cannot be perfectly offset just because consumers always have access to some credit. In this model, the effects of income shocks are amplified by their influence on the time-varying credit limit. Bad income draws tighten the credit constraint when the consumer is likely to need it most, ${ }^{26}$ hence the need for consumption smoothing when resources are relatively plentiful. However, the agent is impatient and dislikes saving. It is only when resources are suf-

\footnotetext{
${ }^{26}$ This depends on the recent history of income draws and how much debt has been accumulated.
} 
ficiently high that precautionary motives take over and encourage the household to leave a buffer between what it is eligible to borrow and what it does borrow.

Figures $2 \mathrm{a}$ and $2 \mathrm{~b}$ differ in two notable respects. First, the branches in Figure $2 \mathrm{a}$ (when $\sigma=.05$ ) are closer together than in Figure $2 \mathrm{~b}$ (when $\sigma=0.15$ ). At the same resource ratio, there is less variability in the consumption ratio across states when income growth is less variable. In addition, the policy function for the highest state (lowest branch) levels off at a higher value of $w$ in Figure $2 a$ than it does in Figure $2 b$. When income is less variable, agents are more willing to consume the entire resource pie when they are wealthier than they are when there is more uncertainty.

\section{Time Series Simulations}

In order to gain some insight into the model's predictions for consumption behavior and how it relates to the time series evidence, I use the policy functions derived in the last section and employ simple simulations to repeat the exercise of instrumental variables estimation of consumption growth. In doing so, I assume that the econometrician can observe the level of debt, but not the individual credit limit.

\subsection{Individual consumption}

Before considering the simulated relationship between consumption growth and predictable credit growth, it is useful to document how variation in certain parameters affects the correlation between credit and its upper limit, since the consumer will not in general be constrained in every period, so that debt will not always equal its upper limit. The amount of time spent in the region of the policy function where consumption equals total resources (call this region 1) relative to the amount of time spent in the flatter portion of the figure (region 2), depends on the values of certain key parameters. In particular, it depends upon the balance between impatience and imprudence, or 
the gap between the left and right hand side of equation (13). ${ }^{27}$ In Table 2, I experiment with varying $\delta$ and $\sigma$ in simulations of 160 periods, the sample size of the large U.S. data set. Holding the degree of income variability, $\sigma$, fixed at 0.03 and increasing the rate of time preference, $\delta$, from 0.04 to 0.15 increases the amount of time spent in region 1 relative to region 2 , and therefore the simulated correlation between credit growth, and the growth in the credit limit (income growth) increases from 0.25 to 0.79 . Similarly; with $\delta$ fixed at 0.05 , decreasing $\alpha$ from 0.05 to 0.03 increases the correlation between credit growth and income growth from 0.45 to 0.79 . As discussed below, these correlations are an important factor in determining the relationship between predictable credit growth and consumption growth.

Table 3 presents the results of instrumental variables regressions using simulated data from 100 simulations of the baseline model over 160 periods each. Using one lag of income growth, consumption growth, and credit growth as instruments, the table gives the mean, median, and standard deviation of each of coefficient and its $t$ statistic across simulations. ${ }^{28}$

The first panel gives the results of estimating consumption growth as a function of predictable income growth using the simulated data from the baseline model of individual behavior. Just as in models of fixed borrowing limits, the liquidity constraints produce a statistically significant and positive correlation between expected income growth and consumption growth In bad times, consumption is constrained by current resources which are partly determined by the exogenous income draw. ${ }^{29}$

Rationalizing a positive correlation between consumption growth and predictable credit growth requires more thought. In these simulations, if individuals do not spend enough time, over the 160

\footnotetext{
${ }^{27}$ I think Chris Carroll for providing this intuition.

${ }^{28}$ The lagged debt to income ratio can also be added to this instrument set, or substituted for one of the other instruments, without altering the results fundamentally.

${ }^{29}$ The fact that the point estimate has a magnitude greater than one is a property of the beseline model. To build intuition, consider as an approximation, the change in the level of consumption when it is set equal to $X_{t}$. In this case, using the definition of $\bar{D}_{t}, \Delta C_{t}$ is equal to $\alpha \Delta Y_{t}-1 / \omega \Delta Y_{t-1}$, where $\alpha \equiv 1+1 /(\omega(1+r))$. Then the IV coefficient on $\Delta Y_{t}$ (dependent variable $\Delta C_{t}$ ) where $\Delta Y_{t-1}$ is used as the instrument, is given by $\hat{\gamma}$ $=\operatorname{Cov}\left(\Delta Y_{t-1}, \Delta C_{t}\right) / \operatorname{Cov}\left(\Delta Y_{t}, \Delta Y_{t-1}\right)=\alpha-1 /(\omega \rho)$ where $\rho$ is the autocorrelation coefficient for $\Delta Y_{t}$. Since $\alpha>1$ (about 1.2 for $\omega=5$ ) and $\rho$ is negative (in the baseline model equal to -0.37 for the log difference in income), the point estimates can be larger than one.
} 
period simulation history, constrained by current resources and borrowing up to the credit limit (so that $\Delta d_{t}$ is sufficiently correlated with $\Delta \bar{d}_{t}$ ), the simulations will not produce a positive correlation between $\Delta c$ and $E_{t-1} \Delta d$. To achieve this degree of correlation the consumer must be sufficiently impatient; some experimentation indicated that setting $\sigma$ fairly low at 0.03 and varying $\delta$ between 0.04 and 0.07 worked well. These values are used throughout Table $3 .^{30}$

Panels 2 (with $\delta=0.04$ ) and 3 (with $\delta=0.07$ ) of Table 3 contrast the results of instrumental variables regressions of consumption growth on expected debt growth using the simulated data. The estimated coefficient is positive and statistically significant in both cases. The $t$ statistics are larger in panel 3 where the higher rate of time preference induces a stronger correlation between credit growth and growth in the upper credit limit.

It is worthwhile emphasizing aspects of the model that lead to this result. In periods when resources are sufficiently low, consumption is constrained by the level of resources currently available. Because the upper borrowing limit is an important determinant of how much can be spent, predictable variation in credit growth will have significant effects on consumption growth if debt is sufficiently correlated with its upper limit, or put another way, as long as the degree of impatience is sufficiently higher than the degree of prudence. Obviously, such a correlation between debt and its upper limit cannot exist without variation in the borrowing limit. Therefore, one way $*$ of thinking about how this model rationalizes the correlation between expected credit growth and consumption growth is that the liquidity constraint creates some causality which runs from the time-varying supply of credit to consumption; for consumers that are constrained, how much they can consume depends on the value of their credit limit for the period. ${ }^{31}$

\footnotetext{
${ }^{30}$ Higher values of $\sigma$ decrease the degree of impatience relative to prudence and so reduce the correlation between credit growth and the growth in the upper credit limit, hence reducing the correlation between consumption growth and predictable credit growth. MaCurdy's estimate for this parameter was much higher than the 0.03 used here. It is hard to know how to set this parameter, however, because as Deaton (1991) notes, these estimates are likely inflated as a result of substantial measurement error in recorded income.

${ }^{31}$ This is not to imply that the only type of model which could possibly produce a correlation between consumption growth and some measure of predictable debt must be one in which binding constraints are a necessary part of the story. It seems possible, for example, that a variant of the precautionary saving model considered in Carroll, 1991, where there are no explicit liquidity constraints but where there is voluntary no-borrowing beyond some fixed (nonzero) limit, might also produce such a correlation just as that model with voluntary abstinence from borrowing produces excess sensitivity of consumption growth to predictable income growth. What is required here is a high
} 
The fourth panel of Table 3 estimates consumption growth as a function of both predictable credit growth and predictable income growth. It is possible for each variable to have independent effects because credit is not always set equal to its upper limit, so that credit growth and income growth are not perfectly correlated. For example, suppose debt in period $t+1$ is set to its upper limit, $\bar{d}_{t+1}$, but period $t$ debt is not. - Then predictable credit growth is equal to $E_{t-1}\left(\bar{d}_{t+1}-\right.$

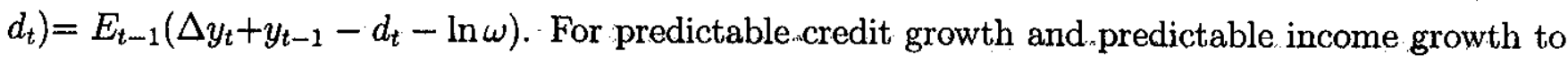
have independent effects on consumption growth, I found that parameters must be chosen so that these variables are sufficiently correlated, (individuals must be sufficiently impatient) but not near perfectly so (there must be enough independent variation to distinguish their separate effects).

Table 3 shows that both expected income growth and expected credit growth are significant predictors of consumption growth. The mean coefficient (over 100 simulations) on income growth is 1.2 , and the mean coefficient on credit growth is 0.73 . Both coefficients are statistically significant at better than the 5 percent level. The average size of both the point estimates and the $t$ statistics, however, are smaller than in regressions where consumption growth is estimated as a function of only one of the variables, reflecting the positive correlation between predictable income growth and predictable credit growth that the model imposes and that is also reflected in the U.S. data.

In summary, the time series simulations of the baseline model show that-borrowing restriations which vary with the income process produce a positive correlation between consumption growth and predictable credit growth.

\subsection{Aggregation}

The last section explored the ways in which a representative agent model can rationalize the evidence on consumption and credit found in U.S. aggregate data. Specifying income as the sum of a random

degree of impatience, something also required of models with a precautionary motive that generate buffering behavior. But in this model, impatience corresponds with the fraction of time constraints bind, and in particular, when the parameter values experimented with here are used, simulations did not produce the type of correlations sought unless $D_{t}=\bar{D}_{t}$ a sufficient number of periods during the simulation history. Hence, within this class of liquidity constraint models, the simulation results depended on this constraint binding often enough. 
walk and white noise is a plausible approximation of individual income, but is a less satisfactory description of aggregate income. It would be nice to relate the microeconomic model in the last section to one that aggregates individual income and consumption decisions in some meaningful way so as to more closely mimic the times series properties of aggregate data.

One possibility is proposed in Deaton (1991). In this section I follow his suggestion to consider $H$ separate individuals. Income growth of each individual can be represented as a decomposition of (9) into three components,

$$
\Delta y_{t}-g=\epsilon_{1, t}+\chi \epsilon_{1, t-1}+\epsilon_{2, t}+\epsilon_{3, t}-\epsilon_{3, t-1}
$$

The first two terms on the right hand side along with the growth rate $g$, make up a growth component common to all consumers and capture the positive correlation in aggregate income growth with positive parameter $\chi . \epsilon_{2}$ is the innovation in an idiosyncratic random walk, while the last two terms are the first difference of idiosyncratic transitory income. Total income for each consumer is the sum of a common $\operatorname{ARIMA}(0,1,1)$, an idiosyncratic random walk and transitory white noise. Once income is aggregated over the $H$ households, the idiosyncratic components cancel each other out, and aggregate income growth is positively autocorrelated. ${ }^{32}$

As before I set $g=0.02$. In addition, I set $\sigma_{1}$, the standard deviation of $\epsilon_{1}$, equal to 0.01 , allowing the two idiosyncratic components to account for most of the income variation at the individual level. $^{33}$ I set $\chi$ equal to 0.5 , implying an autocorrelation coefficient of 0.4 in aggregate income growth. Given the equivalence between (26) and (12) and keeping $\sigma=0.03$, the standard deviation of each idiosyncratic innovation in (26) can be obtained by matching variances and covariances. I

\footnotetext{
${ }^{32}$ To think of this as an aggregate model, assume the existence of firms with access to a linear investment technology, allowing them to earn a constant rate of return by either investing directly, or, alternatively, lending to consumers at this rate.

${ }^{33}$ Although it is possible to narrowly vary $\sigma_{1}$ around this value, its magnitude relative to the standard deviations of each idiosyncratic component is restricted by imposing equivalence between (12) and (26). In particular, to insure real values for the standard deviations of the idiosyncratic components, the relative magnitude cannot be too large since the overall growth process for individual income displays transitory noise.
} 
also follow Deaton by assuming that individuals do not observe the three components separately, but do observe their sum which is equivalent to the representation in (12). This assumption allows for the use of the policy function previously obtained when aggregating individual consumption decisions. $^{34}$

Using the policy functions calculated in the last section, it is now possible to simulate income histories for $H$ individuals, compute consumption deeisions for each of them, and aggregate explicitly. Table 4 gives the results of IV regressions using this aggregate data; for $H=1,000$ households. Since the aggregation procedure changes the autocorrelation in income growth, it changes the cross correlations between the variables and the instruments, so it is natural to expect that different parameter values may be required to achieve the same sort of instrumental variables results produced in the baseline model. Generally, a higher degree of impatience was required to create the desired correlations in the aggregate model. Aggregate consumption growth is regressed on predictable, aggregate credit growth in the first row. Aggregate consumer credit growth is significantly correlated with aggregate consumption growth; the point estimate for $\alpha$ is 0.80 .

The simulation results from the last section suggest that, in principle, it may be possible for predictable income growth and predictable credit growth to simultaneously have explanatory power when they are both included as regressors. The outcome of simulating the baseline: model of individual behavior demonstrates that both variables can be independently meaningful. In practice however, finding the right set of parameter values to do this in the aggregate model proved elusive, and instead the two variables appeared to drive each other out (row 2). It is possible that the parameter values need to be chosen differently, or that this is a property of the aggregation. On a theoretical level, it seemed that the most promising way to begin thinking about the empirical

\footnotetext{
${ }^{34}$ As Deaton (1991) points out, this assumption also implies that individuals cannot observe the aggregate shock. Though this is clearly an unrealistic assumption, Pischke (1995) argues that aggregate information is not very important for individual consumption decisions because individual income is considerably more variable than aggregate income. He uses this presumption to construct a model of consumption behavior that reproduces several observed features of the aggregate data, including the correlation of consumption growth with lagged income growth. Ludvigson (1996a) considers the interaction of liquidity constraints and precautionary savings with complete information and asks whether such a model can account for the observed variability of consumption growth relative to income growth found in aggregate data.
} 
results was to start from the bottom up, with a model of individual behavior that could replicate some of the features in the data. The immediate goal, however, is to compare the model of aggregate " behavior with the results from the U.S. aggregate data, not with those from the baseline model, and here it is the explanatory power of expected credit growth that stands out, generally at the expense of expected income growth.

Still, a familiar but important feature of this framework, and common to other models of liquidity constraints, is that expected income growth has considerable explanatory power in consumption growth regressions. The empirical evidence in section 3, which shows that the explanatory power of predictable income growth is sensitive to whether or not predictable credit growth is included as an additional explanatory variable, therefore presents a puzzle. One possible explanation is that income is measured with error relative to credit. Though this author knows of no evidence that directly evaluates the relative measurement error in these two series, it seems plausible that the former would be more inaccurate than the latter. The reliability of the quarterly national income accounts can be compromised by several distinct sources of error, including lack of appropriate data, errors in seasonal adjustment, and sampling errors and biases..$^{35}$ In contrast, the data on credit are collected from relatively few sources (primarily commercial banks and finance companies) which have an interest in keeping accurate records. If income and credit are positively correlated, then sufficient variability in the measurement error of income could produce the "driving out"result.

The last row of Table 4 makes this point by adding pure measurement error to aggregate income growth. That is, individuals do not observe their own incomes with error when making consumption decisions, only the econometrician does. The table shows the results when a white noise random shock"drawn from $N(0,0.0025)$ is added to income growth before the IV estimation is performed. When both variables are included as regressors, the point estimates for the coefficient on expected income growth, $\lambda$ and for the coefficient on expected credit growth, $\alpha$, are 0.009 and 0.801 respectively, but the $t$ statistics show that income growth now has little explanatory power while credit

\footnotetext{
${ }^{35}$ Allan H. Young "Reliability of the Quarterly National Income and Product Accounts of the United States,
} 1947-1971", Review of Income and Wealth, March 1974, 20(1), pp. 1-39. 
growth remains a strong predictor, a result that is at least qualitatively similar to those found in the aggregate data. This outcome was consistently produced with the variance in the measurement error as low as 0.0025 , but not as low as 0.0001 .

In summary, the results for the simulated macroeconomy presented in this section reproduce some of the findings in the U.S. aggregate data, that predictable credit changes are correlated with changes in consumption. The simulations do not replicate the driving out result, that consumption changes are no longer correlated with previously predictable changes in current income once previously predictable changes in credit are controlled for, unless current income exhibits a suffieient degree of measurement error relative to that of consumer credit. Left open are questions about how much measurement error actually exists, and how the point estimates might come better in line with the data. Next, I turn to a short analysis of credit market deregulation in this setting.

\subsection{Credit market evolution: varying $\omega$}

It has been widely noted that many industrialized nations have undergone a deregulation of their financial systems in the 1980's, and that this has resulted in an increase in the availability of credit to consumers. Campbell and Mankiw (1991) suggest that this, elong with an optimistic outlook for income, is one cause many have ascribed to the decline in personal savings rates in the United Kingdom during the late 1980's. One question that arises is whether this heightened ability to borrow has diminished liquidity constraints enough to enable consumption to move with permanent income. Campbell and Mankiw do several tests in an attempt to detect a decline in the dependence of consumption growth on predictable income growth over time as credit markets have evolved. However, in all of the tests they perform, they fail to find any evidence that consumption is becoming less sensitive to predictable income.

The time series results in Campbell and Mankiw contrast with their cross sectional results and with those of Jappelli and Pagano (1989): countries with better developed credit markets are countries where consumption growth seems to depend less on expected income growth in regressions 
of the former on the latter. The findings of Campbell and Mankiw and Jappelli and Pagano pose interesting questions. Do modest increases in the borrowing limit eliminate the dependence of consumption on current resources? What is the effect on consumption of an unanticipated increase in the credit limit? Is consumption growth less correlated with predictable components of income in countries where the credit limit is higher as a fraction of income? In this section I confront these issues by employing the simple framework developed earlier to simulate a change in $\omega$ over time and cross sectionally.

To simulate a one-time deregulation, or evolution, of the credit market, I assume an unexpected, one-off increase in the credit limit (a decline in $\omega$ ) and then look at the transition to a new state with the higher credit limit. Before moving on to a discussion of the transition characteristics, it is worthwhile noting one caveat about how this exercise relates to the rational expectations framework. The experiment of varying $\omega$ over time imposes technical complications because the solution previously obtained presupposes that $\omega$ will never change. If their credit limit changes once, agents might presume it could change again, and consumption decisions should reflect this probability. Unfortunately, specifying a stochastic credit limit-income ratio would greatly complicate the calculations. A second best alternative is to assume the economy initially operates at the old credit limit, and then undergoes an unexpected, one-off shift to a higher credit limit. If people then follow the law of motion for the new credit limit, the transition path can be simulated explicitly. I view this as a meaningful way to assess the effects of a one-time variation in the credit limit even if modeling a stochastic debt limit-income ratio might be superior.

In order to isolate the effects on consumption and credit of the one-off shift to a higher credit limit and abstract from the effects of fluctuations in income, it is useful to eliminate those fluctuations by examining the transition assuming income growth is equal to its average. Figures 3 and 4 display the results where I ask what the transition looks like if I suppose that income growth is equal to its average in every period in some neighborhood of $T$, the time at which a shift to a higher credit limit occurs. The figure shows transition paths for the case where the individual starts off with $\omega=3$, and then in period $T=2$ in the figures, a one-off shift to a higher credit limit with $\omega=1.5$ 
occurs. As the figures show; both debt and consumption jump up at time $T$.

The increased ability to borrow leads to a short term consumption boom. The consumption ratio jumps up immediately, with consumption growth initially increasing to $12 \%$. There is a short run decline in the dependence of consumption on current income. As Figure 4 demonstrates, however, this only serves to run up credit to the point where constraints bind again, and consumption.must eventually fall in the transition to anew steady state with $\omega=1.5$. Note that debt increases rapidly, reaching its new steady state ratio after about seven periods. The consumption ratio and resource ratio also reach their new values after seven periods. This outcome is broadly consistent with notion that a deregulatory shift in credit markets during the 1980's is somehow related to the surge in consumer spending in that decade.

Note that during the seven period transition, the consumption ratio is always exceeded by the resource ratio, indicating that the Euler equation holds and consumption is not constrained. The dependence of consumption on current resources is not permanently eliminated however (Figure 3). Given the relatively short transition period, it seems unlikely that the consequences of a deregulatory shift of this sort would be detected in consumption growth regressions over many periods, consistent with the time series evidence in Campbell and Mankiw (1991).

Next, I compare two islands that differ solely through how much credit is available as a fraction income, so that one island's credit market is more "evolved"than the other's. Is the explanatory power of predictable income growth less in the more evolved island? Table 7 suggests not. The table shows the outcome of IV regressions of aggregate consumption growth on expected, aggregate income growth, comparing the results when $\omega=3$ with those when $\omega=5$. Although the $t$ statistic for the coefficient on predictable income growth is somewhat smaller on average when the credit limit is higher, the point estimate is strongly significant in both cases. A borrowing limit that is a larger, fixed amount of income is not the same as allowing any level of indebtedness in any period, and so consumers who can borrow one and two thirds times more as a fraction of their income do not necessarily find their consumption unconstrained by current resources. 
The simulations in this section indicate that, with sufficiently impatient consumers, access to more credit does not necessarily lead to a permanent decline in the dependence of consumption growth on current resources. This is consistent with the time series evidence in Campbell and Mankiw (1991), but seems to contrast with cross sectional findings that consumption growth is less dependent on predictable income in countries where consumer credit is more widely available. The model may still provide a way of thinking about the apparent discrepancy however.

Suppose, as the framework here indicates, more credit does not necessarily mean less binding constraints. If expected income growth and expected credit growth are correlated, making cross.sectional inferences about the relative severity of liquidity constraints from regressions of consumption growth on the expected growth in income alone, may be misleading. For example, suppose countries with the least developed credit markets are also countries in which informational problems about the ability of borrowers to repay are most severe. Then one would expect borrowing restrictions in these countries might be more closely tied to observables such as income, so that even though there is less credit available, what is available is more highly correlated with net worth. But the theory in this paper predicts that expected credit growth will then have important effects on consumption growth. In addition, the empirical results have exhibited a positive correlation between expected income growth and expected credit growth. This suggests that leaving expected credit growth out of the consumption growth regression may bias the coefficient on income growth upward in countries with less developed credit markets relative to countries in which credit markets are more developed. Jappelli and Pagano's findings even hint that international variation in this kind of informational asymmetry may exist: They find that countries with the smallest credit markets tend to require the largest down payments on mortgages. Controlling for predictable credit growth as an additional.explanatory variable may eliminate the potentially large omitted variables bias, leading to a different cross sectional pattern of results. 


\section{$5 \quad$ Summary and concluding remarks}

This paper has displayed evidence that consumption growth is correlated with predictable consumer credit growth. The finding presents a puzzle for students of consumption behavior because it is not readily explained by existing models of agents, constrained or unconstrained, forming rational expectations over the extended future. I have argued that a simple modification of the more familiar liquidity constraint model with fixed borrowing restrictions can qualitatively replicate such a correlation. To do so the model requires, both that borrowing limits vary over time, and that they vary with current income. The framework makes two predictions that are consistent with findings from the U.S. aggregate data: changes in consumption are significantly correlated with predictable changes in consumer credit, and instrumental variable forecasts of income growth are correlated with those of consumer credit growth. In addition, the model demonstrates that modest increases in borrowing limitations may not permanently leave consumption unconstrained for consumers who are impatient and therefore apt to borrow in the first place. Instead, a deregulatory shift of this type may lead to a short term consumption boom, an outcome consistent with the notion that changing credit market conditions were associated with the surge in consumer spending in the 1980's.

The findings are economically significant in several ways. First, adverse shocks to the economy are likely to be amplified and aggravated by the type of procyclical borrowing restrictions considered here; hence the results suggest that a "financial accelerator" of the type Bernanke Gertler and Gilchrist (1995) study for firm production may also be applicable to consumption. Second, large amounts of debt accumulated from previous periods ("debt overhang") lower consumers' resources today, making it more likely that they will be constrained and shocks will be amplified. Finally, the empirical results suggest that various institutional.features of consumer credit markets may have independent effects on real activity. How borrowing restrictions vary over time and with other variables in the consumer's information set, as well as the overall availability of consumer credit, may have important consequences for how much individuals actually do consume.

One possible response to the findings presented here is that preferences are not time-separable 
over non-durables and services consumption. Habit formation is an example of an alternative model that can lead to autocorrelated consumption (Deaton 1992). This would explain the correlation between expected credit growth and consumption growth found here because lagged consumption growth is used as an instrument for predicting credit growth. Of course, this model also predicts that lagged consumption growth should be correlated with current consumption growth because it is useful in predicting current eredit growth. It is difficult to think of a test that would unambiguously sort out this possibility from the explanation considered here. One hopes that the over-identification tests would fail in the event that lagged consumption growth should be in the regression for habits, but even that poses a potential problem because it is uninformative when the model is just-identified. Support for the idea that time-varying liquidity constraints play a role, however, is given in Ludvigson (1996b), who finds evidence from the market for automobile credit that procyclical variation in the availability of bank consumer credit exists, and that this variability in turn influences real consumption expenditures.

One puzzle that arises from the data and which deserves further inquiry is the apparent sensitivity of predictable income growth, in explaining consumption growth, to whether or not predictable credit growth is included as an explanatory variable. Though it is possible that measurement error in personal income is responsible, this finding is difficult to reconcile within the liquidity constraint framework where the explanatory power of predictable income growth seems to be a general property of the model.

There are several possibilities for further work. First, within the framework of time-varying liquidity constraints, alternative ways of aggregating individual demands could be explored to determine the conditions under which some reasonable composite of the baseline model comes better in line with the aggregate data. Second, I have argued that leaving credit growth out of consumption growth regressions may lead to misleading interpretations about the relative severity of liquidity constraints. In particular, if income is correlated with the time-varying credit limit, then countries with smaller credit markets and more informational problems may display larger coefficients on predictable income growth in consumption growth regressions, not because consumption 
is more dependent on current resources in these countries, but because the regression estimates are subject to omitted variables bias. Data limitations not withstanding, this calls for a reexamination the international data with the aim of better understanding the impact of consumer credit on consumption cross sectionally. Finally, a more challenging direction for future research is to incorporate additional forms of saving behavior into the framework here, since there are obviously some consumers who are not liquidity constrained and who hold large amounts of positive assets. Deaton (1992) has suggested that these consumers may be relatively few but relatively patient individuals who account for a disproportionate share of aggregate saving. Modeling this behavior explicitly could constitute a first step in moving the broader liquidity constrained paradigm to a general equilibrium setting. 


\section{APPENDIX}

This appendix briefly describes the recursive technique used to solve equation (21) in the text. Consider $n$ functions, $p_{o}, p_{1}, \ldots, p_{n}$ where $p=v[f(\cdot)]$. Instead of the infinite horizon, for the moment suppose that $n=0$ corresponds to a final period, so that period 1 is one period before the final period and period $n$ is $n$ periods before the final period, or the first period. Then (21) can be re-written as an updating rule,

$$
p_{n}(\cdot)=\max \left[v(w), \beta^{\star} \sum_{j} \pi_{j} \rho_{i j}^{\gamma} p_{n-1}\left\{\left[1+\rho_{i j}(1+r)\left(w-v^{-1} p_{n}(\cdot)+\zeta_{i j}\right], j\right\}\right]\right.
$$

where $\rho_{i, j}$ and $\zeta_{i, j}$ are as given in (21) and (22). Suppose in the final period, all resources are spent, so that $\theta=f(w, \eta)=w$, and $p_{o} \equiv v(w)$. In principle, one can working backwards, giving the first iteration $p_{n}$ on the right hand side, and the quantity in brackets can be explicitly computed, yielding a new $p_{n}$ used to determine whether a convergence criterion has been satisfied, in which case we have the optimal policy, $p$, the solution to the infinite horizon problem. If the convergence criterion has not been satisfied, the quantity in brackets is denoted $p_{1}$, giving the second iteration $p_{n}$ to be plugged in the right hand side of (A.1), and so on. Under appropriate conditions (are ready established by Deaton and Laroque (1992) for this problem) the mapping is a contraction, and the backward solution will converge in a finite number of iterations to a unique solution. In practice, it is easier to replace $p_{n}$ on the right hand side with $p_{n-1}$ and set $p_{0}=v(w)$. If the convergence criterion can be satisfied with this replacement, we have found the optimal policy, since (A.1) is a contraction and guarantees a unique solution for $p$. 


\section{References}

[1] Ainslie, George, 1993, "Derivation of 'Rational 'Economic Behavior from Hyperbolic Discount Curves", American Economic Review Papers and Proceedings , 81, 334-340.

[2] Bernanke, Ben and Mark Gertler, 1989, "Agency Costs, Net Worth, and Business Fluctuations", American Economic Review, LXXIX, 14-31.

[3] Bernanke, Ben, Mark Gertler and Simon Gilchrist, 1995 "The Financial Accelerator and the Flight to Quality", Review of Economic Studies (forthcoming).

[4] Blanchard, Olivier, 1993, "Consumption and the Recession of 1990-1991 ", American Economic Review Papers and Proceedings, 83, 270-274.

[5] Campbell, John Y., and Greg Mankiw, 1989, Consumption, Income and Interest Rates: Reinterpreting the Time Series Evidence ; in: O. Blanchard and S. Fischer, eds.; NBER macroeconomics annual 1989 (MIT press).

[6] Campbell, John Y., and Greg Mankiw, 1990, "Permanent income, current income and consumption", Journal of Business and Economic Statistics, 8, 269-279.

[7] Campbell, John Y., and Greg Mankiw, 1991, "The Response of Consumption to Income, A cross-country investigation.", European Economic Review , 35, 723-767.

[8] Carroll, Christopher, 1991, "Buffer Stock Saving and the Permanent Income Hypothesis", Board of Governors of the Federal Reserve Working Paper No. 114.

[9] Carroll, Christopher, Jeffrey Fuhrer, and David Wilcox; 1994;"Đoes consumer sentiment forecast household spending? If so why?", American Economic Review, 84(5), 1397-1408.

[10] Deaton, Angus, 1991 "Saving and Liquidity Constraints. ", Econometrica, 59, No. 5, 1221-1248.

[11] Deaton, Angus, 1992, Understanding Consumption, Oxford University Press. 
[12] Deaton, Angus, and Guy Laroque, 1992, "On the Behavior of Commodity Prices", Review of Economic Studies, 59, 1-23.

[13] Fazzari, Steven M., Glenn Hubbard and Bruce Petersen, 1988, "Financing constraints and corporate investment", Brookings Papers on Economic Activity, 1:1988, 141-206.

[14] Fisher, Jonas D.M., and Andreas Hornstein, 1994, "Optimal (S,s) Inventory Policies in General Equilibrium", unpublished manuscript, University of Western Ontario.

[15] Flavin, Marjorie, 1981, "The Adjustment of Consumption to Changing Expectations About Future Income", Journal of Political Economy, 89, 974-1009.

[16] Hall, Robert E., 1978, "Stochastic Implications of the Life Cycle-Permanent Income Hypothesis: Theory and Evidence...'Lournal of Political Economy, 86, 971-987.

[17] Hall, Robert E., 1993, "Macro Theory and the Recession of 1990-1991", American Economic Review Papers and Proceedings, 83, 275-279.

[18] Hall, Robert E., and Frederic S. Mishkin, 1982, "The Sensitivity of Consumption to Transitory Income: Estimates from Panel Data on Households", Econometrica, 50(2), 461-81. .

[19] Hansen, Lars P. and Kenneth J. Singleton, 1983, "Stochastic Consumption, Risk Aversion, and the Temporal behavior of Asset Returns.", Journal of Political Economy, 91:249-65.

[20] Jappelli, Tullio, and Marco Pagano, 1989, "Consumption and Capital Market Imperfections: An International Comparison", The American Economic Review, 79 (5), 1088-1105.

[21] Judd, Kenneth L., 1991, "Numerical methods in economics", Unpublished manuscript, Hoover Institution, Stanford University.

[22] Kim, Chulsoo, 1992, "Asymmetry in Consumption ", Rutgers University mimeo.

[23] King, Mervyn, 1993 "Debt Deflation: Theory and Evidence ", European Economic Review Papers and Proceedings, 1993. 
[24] Ludvigson, Sydney C., 1996a, "Can liquidity constraints explain the observed variability of aggregate consumption?", unpublished manuscript, Princeton University.

[25] Ludvigson, Sydney C., 1996b, "The mechanism of monetary transmission to demand: evidence from the market for automobile credit", unpublished doctoral dissertation, Princeton University.

[26] MaCurdy, T.E., 1982, "The Use of Time Series Processes to Model the Error Structure of Earnings in Longitudinal Data Analysis. ", Journal of Econometrics 18, 83- 114.

[27] Mankiw, N. Gregory,'1981, "The Permanent Income Hypothesis and the Real Interest Rate.", Economic Letters, 7:307-11.

[28] Pischke, Jörn-Steffen, 1995, "Individual Income, Incomplete Information and Aggregate Consumption ", Econometrico, $63(4), 805-840$.

[29] Shea, John, 1993, "Instrument relevance in linear models: a simple measure", Unpublished manuscript, University of Wisconsin-Madison.

[30] Staten, Michael E., and Robert W. Johnson, 1995, Household Credit Data Book, West Lafayette, Indiana: Credit Research Center Purdue University.

[31] Tauchen, G., 1986, "Finite State Markov Chain Approximations to Univariate and Vector Autoregressions ", Economic Letters, 20, 177-181.

[32] Zeldes, Steve, 1989, "Consumption and Liquidity Constraints: An Empirical Investigation", Journal of Political Economy 97, 305-346. 


\section{Table 1a}

Results from U.S. data

Dependent variable is $\Delta c_{t}$

Second stage, Installment credit 1953:1-1993:1

\begin{tabular}{|c|c|c|c|c|c|c|c|}
\hline$E_{t \cdot 1} \Delta y_{t}$ & $\begin{array}{l}0.360^{*} \\
(3.2)\end{array}$ & ---- & $\begin{array}{c}0.385^{*} \\
(3.5)\end{array}$ & $\begin{array}{l}0.161 \\
(1.1)\end{array}$ & $\begin{array}{l}0.205 \\
(1.5)\end{array}$ & $\begin{array}{l}0.237 \\
(1.5)\end{array}$ & $\begin{array}{l}0.313^{*} \\
(3.2)\end{array}$ \\
\hline$E_{t-1} r_{t}$ & --..- & -.-- & $\begin{array}{c}0.017 \\
(0.90)\end{array}$ & $\begin{array}{l}0.006 \\
(0.36)\end{array}$ & $\begin{array}{l}0.007 \\
(0.37)\end{array}$ & $\begin{array}{l}0.008 \\
(0.48)\end{array}$ & $\begin{array}{l}0.005 \\
(0.29)\end{array}$ \\
\hline$E_{t-1} \Delta d_{t+1}$ & --.-- & $\begin{array}{l}0.102^{*} \\
(3.2)\end{array}$ & $\cdots$ & $\begin{array}{l}0.090^{\circ} \\
(2.6)\end{array}$ & $\begin{array}{l}0.078^{\circ} \\
(2.0)\end{array}$ & $\begin{array}{l}0.085^{\circ} \\
(2.6)\end{array}$ & $\begin{array}{l}0.080^{\circ} \\
(2.4)\end{array}$ \\
\hline Instr. & set 1 & set 2 & set 3 & set 4 & set 5 & set 6 & set 7 \\
\hline
\end{tabular}

First stage, Installment credit 1953:1-1993:1

\begin{tabular}{|c|c|c|c|c|c|c|c|}
\hline $\begin{array}{l}\mathrm{R}^{2} \text { OLS } \\
(\Delta \mathrm{y})\end{array}$ & $0.056^{*}$ & ---.- & $0.050^{\circ *}$ & 0.030 & $0.051^{* *}$ & -0.003 & $0.080^{*}$ \\
\hline $\begin{array}{l}\mathrm{R}^{2} \text { OLS } \\
\left(\Delta \mathrm{d}_{t+1}\right)\end{array}$ & ...-. & $0.430^{\circ}$ & -..-.- & $0.566^{\circ}$ & $0.495^{\circ}$ & $0.497^{*}$ & $0.572^{*}$ \\
\hline $\begin{array}{l}\text { Test of } \\
\text { Rest. }\end{array}$ & 7.02 & 5.82 & 12.30 & 12.64 & 10.35 & 12.34 & 18.21 \\
\hline Instr. & set 1 & set 2 & set 3 & set 4 & set 5 & set 6 & set 7 \\
\hline
\end{tabular}

* Significance at the $5 \%$ or better level

** Significance at the $10 \%$ or better level

Notes: Instruments: set 1: lags 2 through 4 of income growth, consumption growth, and lag 2 of the error correction term, EC, (log difference of consumption and income); set 2: same as set 1; set 3: same as set 1, plus lags 2 through 4 of the real interest rate; set 4: lags 2 through 4 of consumption growth, credit growth, and the real interest rate, and the EC term; set 5: lags 2 through 4 of consumption growth, income growth, the real interest rate and the EC term; set 6: lags 2 through 4 of credit growth, income growth, the real interest rate and the EC term; set 7: lags 2 through 5 of consumption growth, income and credit growth, the real interest rate, and EC. The rows in the first two panels report the instrumental variables estimates of $\lambda, \theta$, and $\alpha$; in parenthesis are the $t$ statistics for the null hypothesis that the coefficients is zero. The last two panels report the adjusted $R^{2}$ for the OLS regression of income and credit growth on the 
instruments; stars indicate the joint marginal significance value for the null hypothesis that all the coefficients except the constant are zero. The row labeled "Test of Restrictions" reports $T * R^{2}$ from an OLS regression of the residual from the IV regression on the instruments.

Table 1b

Results from U.S. data

Dependent variable is $\Delta \mathrm{c}_{\mathrm{t}}$

Second stage, Revolving credit 1978:1-1993:1

\begin{tabular}{lccc}
\hline $\mathrm{E}_{\mathrm{t}-1} \Delta \mathrm{y}_{\mathrm{t}}$ & 0.265 & 0.283 & 0.275 \\
& $(1.58)$ & $(1.60)$ & $(1.60)$ \\
$\mathrm{E}_{\mathrm{t}-1} \mathrm{r}_{\mathrm{t}}$ & 0.012 & $\cdots$ & $\cdots$ \\
& $(0.52)$ & & \\
$\mathrm{E}_{\mathrm{t}-1} \mathrm{pr}$ & $-\cdots$ & 0.025 & $\cdots$ \\
& & $(1.14)$ & \\
$\mathrm{E}_{\mathrm{t} \cdot \mathrm{1}} \Delta \mathrm{d}_{\mathrm{t}+1}$ & $0.110^{\circ}$ & $0.112^{*}$ & $0.111^{*}$ \\
\hline
\end{tabular}

First stage, Revolving credit 1978:1-1993:1

\begin{tabular}{lccc}
\hline $\begin{array}{l}\mathrm{R}^{2} \text { OLS } \\
\left(\Delta \mathrm{y}_{\mathrm{t}+1} \text { on Inst }\right)\end{array}$ & -0.02 & -0.04 & -0.01 \\
$\begin{array}{l}\mathrm{R}^{2} \text { OLS } \\
\left(\Delta \mathrm{d}_{\mathrm{t}+1} \text { on Inst }\right)\end{array}$ & $0.465^{*}$ & $0.450^{*}$ & $0.412^{*}$ \\
$\begin{array}{l}\text { Test of } \\
\text { Restrictions }\end{array}$ & 13.24 & 11.19 & 8.29 \\
\hline
\end{tabular}

Notes: Instruments: Two lags of consumption growth, income growth, revolving credit growth, the interest rate and the error correction term, lag two of the log consumption to income ratio. $r$ is the interest rate on a 3 month treasury bill, pr is the prime lending rate charged by commercial banks. Other notes, see Table la. 
Table 2

Results using simulated data from the baseline model

\begin{tabular}{cc}
\multicolumn{2}{c}{$\sigma=0.03$} \\
\hline$\delta$ & $\operatorname{Corr}(\Delta \mathrm{d}, \Delta \mathrm{y})$ \\
0.04 & 0.247 \\
0.07 & 0.603 \\
0.15 & 0.788 \\
\hline \multicolumn{3}{c}{$\delta=0.05$} \\
\hline$\sigma$ & $\operatorname{Corr}(\Delta \mathrm{d}, \Delta \mathrm{y})$ \\
0.05 & 0.445 \\
0.03 & 0.793 \\
\hline
\end{tabular}


Table 3

IV Results using simulated data from the baseline model

Model: $\Delta c_{t}=\mu+\lambda E_{t-1} \Delta y_{t}+\alpha E_{t-1} \Delta d_{t+1}$

\begin{tabular}{|c|c|c|c|c|}
\hline \multicolumn{5}{|c|}{$\delta=.04, \omega=5$} \\
\hline & $\lambda$ est. & $\alpha$ est. & $\mathrm{t}-\lambda$ & $t-\alpha$ \\
\hline Mean & 1.40 & --- & 26.98 & -.. \\
\hline Median & 1.38 & $\ldots$ & 26.63 & $\cdots$ \\
\hline St. Dev. & 0.08 & --- & 8.09 & -- \\
\hline \multicolumn{5}{|c|}{$\delta=.04, \omega=5$} \\
\hline & $\lambda$ est. & $\alpha$ est. & $\mathrm{t}-\lambda$ & $t-\alpha$ \\
\hline Mean & --- & 2.06 & --- & 5.73 \\
\hline Median & --- & 2.02 & -- & 5.71 \\
\hline St. Dev. & -- & 0.79 & -- & 2.31 \\
\hline \multicolumn{5}{|c|}{$\delta=.07, \omega=5$} \\
\hline & $\lambda$ est. & $\alpha$ est. & $\mathrm{t}-\lambda$ & $t-\alpha$ \\
\hline Mean & $\cdots$ & 2.24 & -- & 7.24 \\
\hline Median & $-\cdots$ & 2.16 & -- & 7.34 \\
\hline St. Dev. & --- & 0.68 & -- & 2.35 \\
\hline \multicolumn{5}{|c|}{$\delta=.04, \omega=5$} \\
\hline & $\lambda$ est. & $\alpha$ est. & $\mathrm{t}-\lambda$ & $t-\alpha$ \\
\hline Mean & 1.16 & 0.78 & 8.97 & 2.55 \\
\hline Median & 1.18 & 0.66 & 8.58 & 2.40 \\
\hline St. Dev. & 0.17 & 0.35 & 4.28 & 0.69 \\
\hline
\end{tabular}

Notes: Dashed lines indicate the variable with the corresponding coefficient in the column was not included as an explanatory variable in the IV regression. The entries in each cell give the mean, median and standard deviation of each coefficient and their $t$ statistics across 100 simulations of 160 periods each. The columns labeled "t-." give the $t$ statistics for that coefficient. Instruments: lag 1 of income growth, credit growth and consumption growth; a constant is included as a regressor and an instrument. 
Table 4

IV Results using simulated aggregate data

Model: $\Delta c_{t}=\mu+\lambda E_{t-1} \Delta y_{t}+\alpha E_{t-1} \Delta d_{t+1}$

\begin{tabular}{ccccc}
\multicolumn{5}{c}{$\delta=.15, \omega=5$} \\
\hline Row \# & $\lambda$ est. & $\alpha$ est. & $\mathrm{t}-\lambda$ & $\mathrm{t}-\alpha$ \\
\hline 1 & --- & 0.795 & -- & 13.40 \\
2 & -4.43 & 5.21 & -0.48 & 0.07 \\
3 & 0.009 & 0.801 & 0.059 & 5.29 \\
\hline
\end{tabular}

Notes: Data are simulated for 1,000 households. Dashed lines indicate the coefficient corresponding to the variable in the column is not included as a regressor. Instruments: one lag of aggregate income growth, consumption growth, and debt growth. The entries in each column give the mean of the coefficient and its $t$ statistic over 100 simulations of 160 periods each. Row 3 runs the regression assuming the econometrician observes income growth measurement error distributed $\mathrm{N}(0,0.0025)$.

\section{Table 5}

IV Results using simulated aggregate data

Model: $\Delta c_{t}=\mu+\lambda E_{t-1} \Delta y_{t}$

\begin{tabular}{ccc}
\multicolumn{3}{c}{$\delta=.04$} \\
\hline & $\lambda$ est. & $\mathrm{t}-\lambda$ \\
\hline$\omega=3$ & 0.94 & 10.71 \\
$\omega=5$ & 0.92 & 13.94 \\
\hline
\end{tabular}

Notes: Data are simulated for 1,000 households. The numbers in the column labeled " $\lambda$ est." are the mean coefficients on expected, aggregate income growth over 100 simulations of 160 periods each. The column labeled "t- $\lambda$ " give the mean $t$ statistics for $\lambda$ over 100 simulations. Instruments: one lag of income growth, consumption growth. 


\section{Percent}

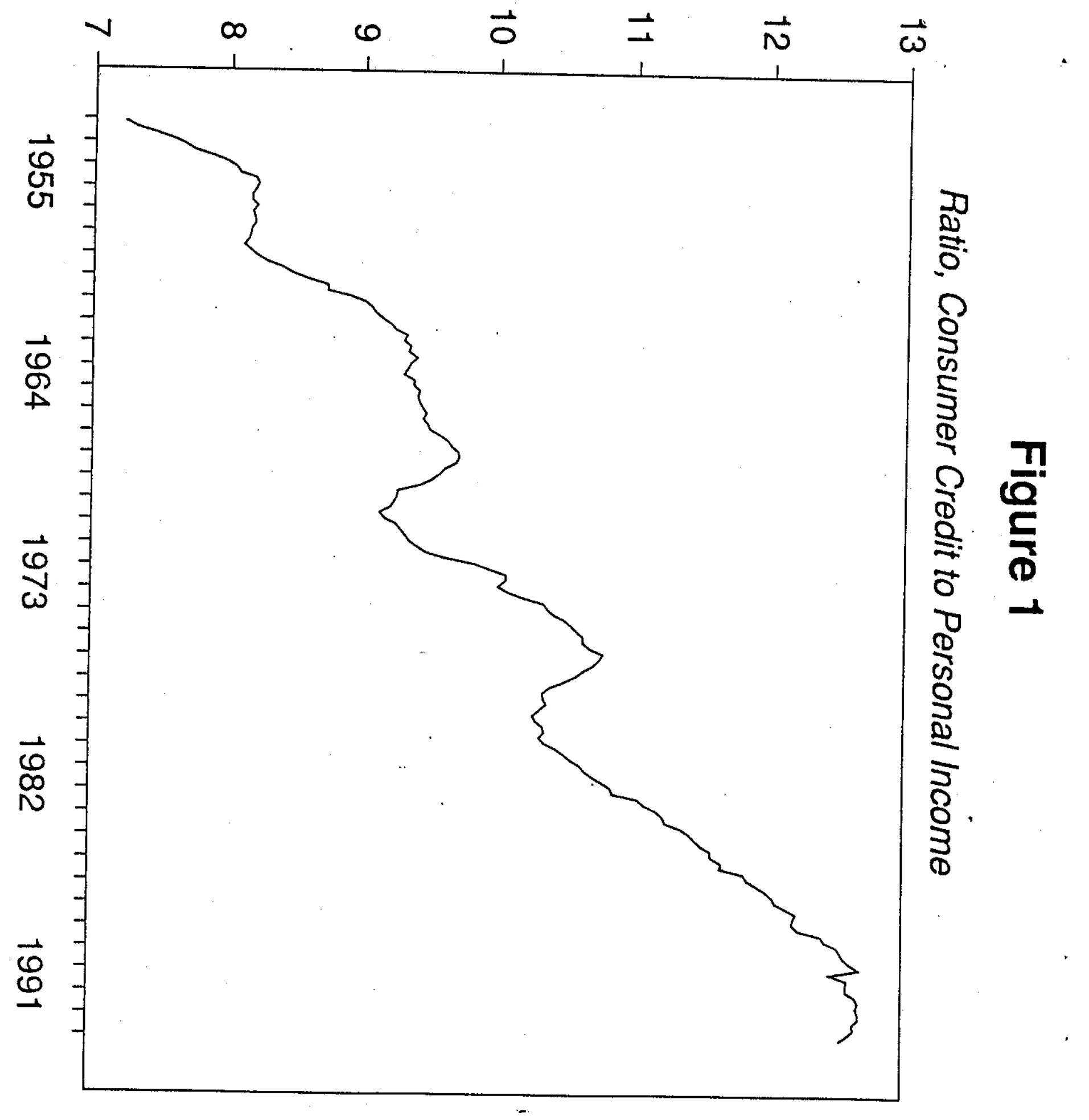




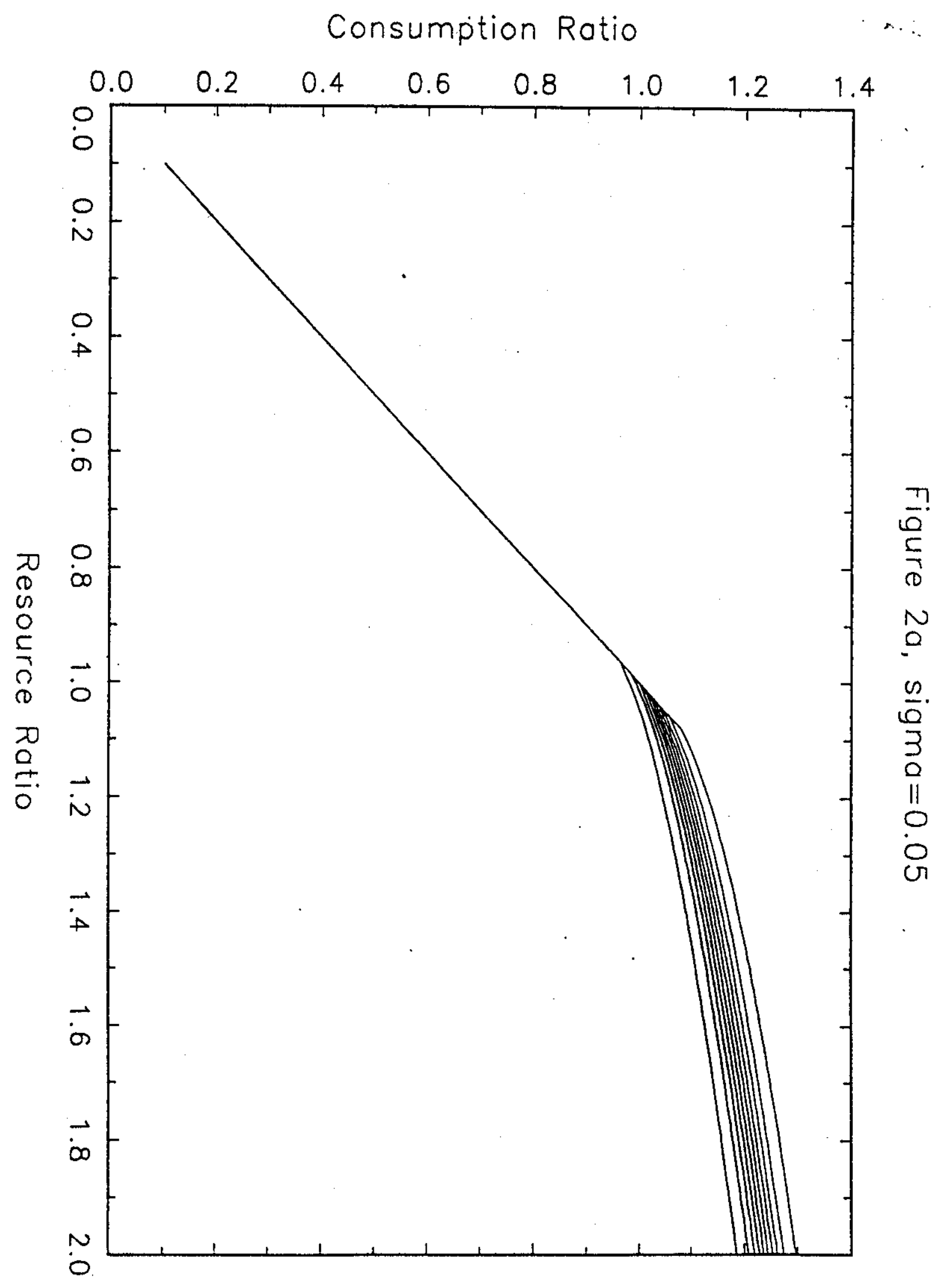




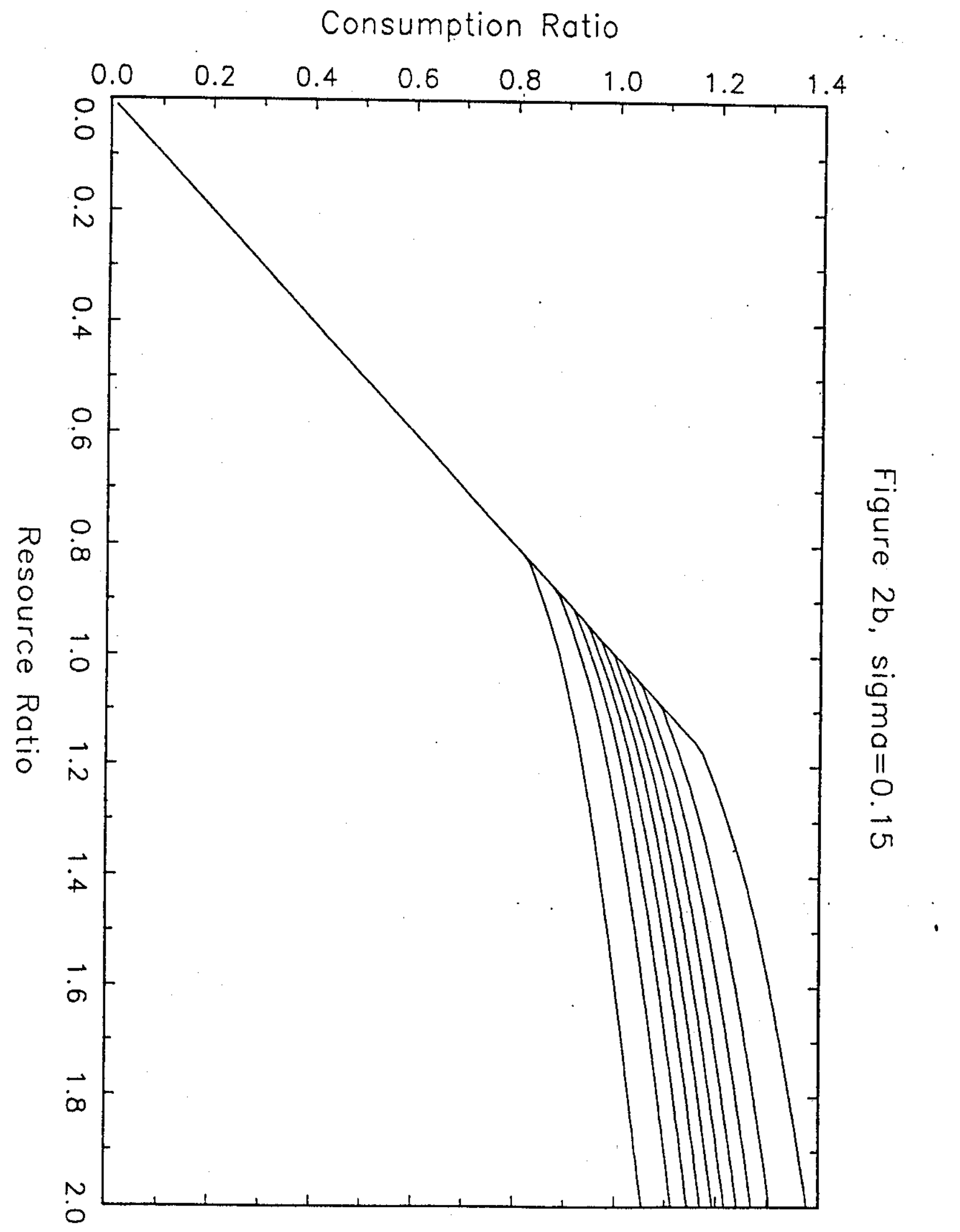




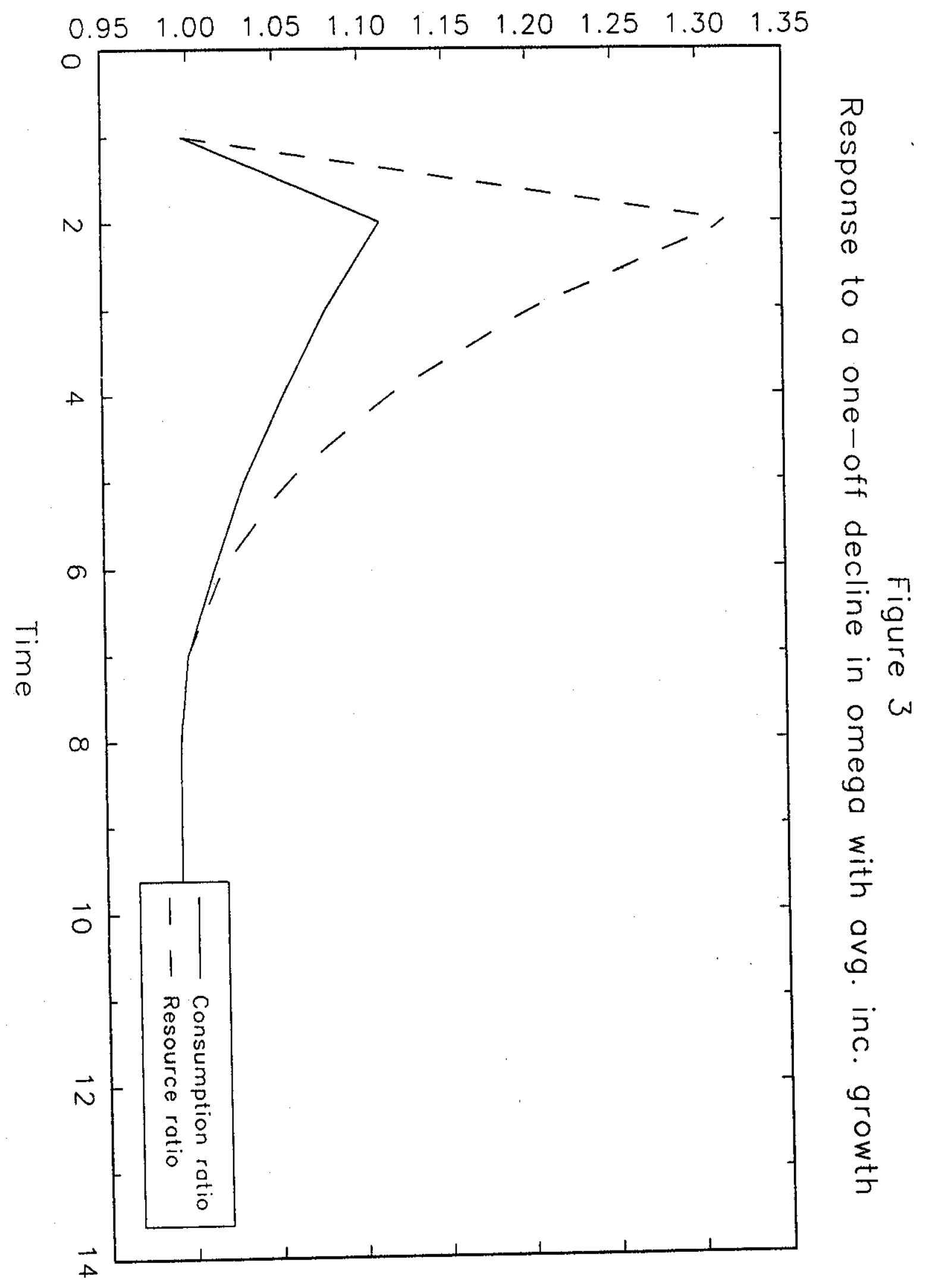




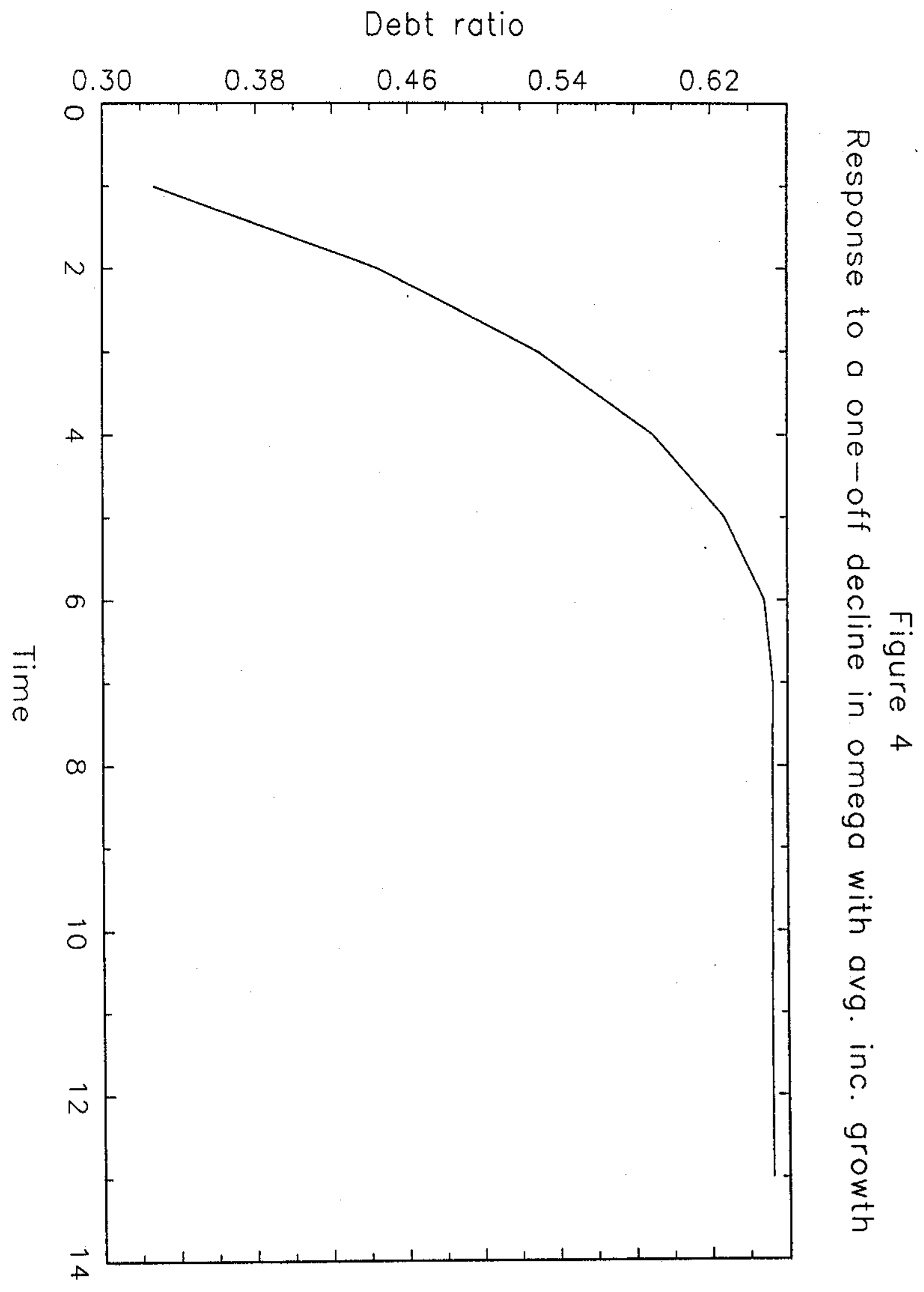




\section{FEDERAL RESERVE BANK OF NEW YORK RESEARCH PAPERS \\ 1996}

The following papers were written by economists at the Federal Reserve Bank of New York either alone or in collaboration with outside economists. Single copies of up to six papers are available upon request from the Public Information Department, Federal Reserve Bank of New York, 33 Liberty Street, New York, NY 10045-0001 (212) 720-6134.

9601. Bartolini, Leonardo, and Gordon M. Bodnar. "Are Exchange Rates Excessively Volatile? And What Does 'Excessively Volatile' Mean, Anyway?" January 1996.

9602. Lopez, Jose A. "Exchange Rate Cointegration Across Central Bank Regime Shifts." January 1996.

9603. Wenninger, John, and Daniel Orlow. "Consumer Payments Over Open Computer Networks." March 1996.

9604. Groshen, Erica L. "American Employer Salary Surveys and Labor Economics Research: Issues and Contributions." March 1996.

9605. Uctum, Merih. "European Integration and Asymmetry in the EMS." April 1996.

9606. de Kock, Gabriel S. P., and Tanya E. Ghaleb. "Has the Cost of Fighting Inflation Fallen?" April 1996.

9607. de Kock, Gabriel S. P., and Tania Nadal-Vicens. "Capacity Utilization-Inflation Linkages: A CrossCountry Analysis." April 1996.

9608. Cantor, Richard, and Frank Packer. "Determinants and Impacts of Sovereign Credit Ratings." April 1996.

9609. Estrella, Arturo, and Frederic S. Mishkin. "Predicting U.S: Recessions: Financial Variables as Leading Indicators." May 1996.

9610. Antzoulatos, Angelos A. "Capital Flows and Current Account Deficits in the 1990s: Why Did Latin American and East Asian Countries Respond Differently?" May 1996.

9611. Locke, Peter R., Asani Sarkar, and Lifan Wu. "Did the Good Guys Lose? Heterogeneous Traders and Regulatory Restrictions on Dual Trading." May 1996.

9612. Locke, Peter R., and Asani Sarkar. "Volatility and Liquidity in Futures Markets." May 1996.

9613. Gong, Frank F., and Eli M. Remolona. "Two Factors Along the Yield Curve." June 1996. 
9614. Harris, Ethan S., and Clara Vega. "What Do Chain Store Sales Tell Us About Consumer Spending?" June 1996.

9615. Uctum, Merih, and Michael Wickens. "Debt and Deficit Ceilings, and Sustainability of Fiscal Policies: An Intertemporal Analysis." June 1996.

9616. Uctum, Merih, and.Michael Aglietta: "Europe and the Maastricht Challenge." June 1996....;

9617. Laster, David, Paul Bennett, and In Sun Geoum. "Rational Bias in Macroeconomic Forecasts." July 1996.

9618. Mahoney, James M., Chamu Sundaramurthy, and Joseph T. Mahoney. "The Effects of Corporate Antitakeover Provisions on Long-Term Investment: Empirical Evidence." July 1996.

9619. Gong, Frank F., and Eli M. Remolona. "A Three-Factor Econometric Model of the U.S. Term Structure." July 1996.

9620. Nolle, Daniel E., and Rama Seth. "Do Banks Follow Their Customers Abroad?" July 1996.

9621. McCarthy, Jonathan, and Charles Steindel. "The Relative Importance of National and Regional Factors in the New York Metropolitan Economy." July 1996.

9622. Peristiani, S., P. Bennett, G. Monsen, R. Peach, and J. Raiff. "Effects of Household Creditworthiness on Mortage Refinancings." August 1996.

9623. Peristiani, Stavros. "Do Mergers Improve the X-Efficiency and Scale Efficiency of U.S. Banks? Evidence from the 1980s." August 1996.

9624. Ludvigson, Sydney. "Consumption and Credit: A Model of Time-Varying Liquidity Constraints." August 1996.

9625. Ludvigson, Sydney. "The Channel of Monetary Transmission to Demand: Evidence from the Market for Automobile Credit." August 1996. 